Soci al memory, ammesi a, and aut i sm $\mathrm{Br}$ ai $\mathrm{n}$ oxyt oci $n$ secreti on is regul at ed by NAD + met abol ites and si ngl e nucl eot i de pol ynor phi sns of CD38

\begin{tabular}{|l|l|}
\hline 著者 & $\begin{array}{l}\text { H gashi da Har uhi ro, Yokoyana Shi ger u, Huang } \\
\text { Ji an- Jun, Li u Li, Na Wen- Ji e, Akt her Shi ri n, } \\
\text { H gashi da Chi har u, K kuchi M t sur u, M nabe } \\
\text { Yoshi o, Munesue Toshi o }\end{array}$ \\
\hline $\begin{array}{l}\text { j our nal or } \\
\text { publ i cat i on ti t l e }\end{array}$ & Neur ochem st ry I nt er nat i onal \\
\hline vol une & 61 \\
\hline nunber & 6 \\
\hline page r ange & $828-838$ \\
\hline year & $2012-11-01$ \\
\hline URL & ht t p: //hdl . handl e. net /2297/32816 \\
\hline
\end{tabular}




\section{Social memory, amnesia, and autism: brain oxytocin secretion is regulated by NAD+ metabolites and single nucleotide polymorphisms of CD38}

Haruhiro Higashida ${ }^{1,2,3,4,}$, Shigeru Yokoyama ${ }^{1,2,3,4}$, Jian-Jun Huang ${ }^{1,3}$, Li $\mathrm{Liu}^{1,3}$, Wen-Jie $\mathrm{Ma}^{1,3}$, Shirin Akther ${ }^{1,3}$, Chiharu Higashida ${ }^{1,2,3}$, Mitsuru Kikuchi $^{2,3,4}$, Yoshio Minabe ${ }^{2,4}$, and Toshio Munesue $e^{2,3,4}$

${ }^{1}$ Department of Biophysical Genetics, Kanazawa University Graduate School of Medicine, Kanazawa 920-8640, Japan

${ }^{2}$ Kanazawa University Center for Child Mental Development, Kanazawa 920-8640, Japan

${ }^{3}$ Core Research for Evolutional Science and Technology (CRESTO), Tokyo 102-0075, Japan

${ }^{4}$ MEXT Strategic Research Program for Brain Science (SRPBS), Okazaki 444-0840, Japan

*Corresponding author. Kanazawa University Graduate School of Medicine, 13-1 Kanazawa 920-8640, Japan,

E-mail address: haruhiro@med.kanazawa-u.ac.jp). 


\section{Abstract}

Previously, we demonstrated that CD38, a transmembrane protein with ADP-ribosyl cyclase activity, plays a critical role in mouse social behavior by regulating the release of oxytocin (OXT), which is essential for mutual recognition. When CD38 was disrupted, social amnesia was observed in $C d 38$ knockout mice. The autism spectrum disorders (ASDs), characterized by defects in reciprocal social interaction and communication, occur either sporadically or in a familial pattern. However, the etiology of ASDs remains largely unknown. Therefore, the theoretical basis for pharmacological treatments has not been established. Hence, there is a rationale for investigating single nucleotide polymorphisms (SNPs) in the human CD38 gene in ASD subjects. We found several SNPs in this gene. The SNP rs3796863 (C > A) was associated with high-functioning autism (HFA) in American samples from the Autism Gene Resource Exchange. Although this finding was partially confirmed in low-functioning autism subjects in Israel, it has not been replicated in Japanese HFA subjects. The second SNP of interest, rs1800561 (4693C > T), leads to the substitution of an arginine (R) at codon 140 by tryptophan (W; R140W) in CD38. This mutation was found in 4 probands of ASD and in family members of 3 pedigrees with variable levels of ASD or ASD traits. The plasma levels of OXT in ASD subjects with the R140W allele were lower than those in ASD subjects lacking this allele. The OXT levels were unchanged in healthy subjects with or without this mutation. One proband with the R140W allele receiving intranasal OXT for approximately 3 years showed improvement in areas of social approach, eye contact and communication behaviors, emotion, irritability, and 
aggression. Five other ASD subjects with mental deficits received nasal OXT for various periods; three subjects showed improved symptoms, while 2 showed little or no effect. These results suggest that SNPs in CD38 may be possible risk factors for ASD by abrogating OXT function and that some ASD subjects can be treated with OXT in preliminary clinical trials.

Key words: CD38, cADPR, TRPM2 channels, oxytocin secretion, social behavior, autism. 


\section{Introduction}

Oxytocin (OXT) is a nonapeptide secreted into the brain from the oxytocinergic neurons in the paraventricular and supraoptic nuclei of the hypothalamus (Brownstein et al., 1980; Neuman et al., 1994 and 1996; Russell et al., 2003; Ludwig and Leng, 2006; Ross and Young, 2009), which is linked to complex social behaviors (Carter, 2003: Insel and Fernald, 2004; Donaldson and Young, 2008; Carter et al., 2009; Skuse and Gallagher, 2009; Ebstein et al., 2009; Insel, 2010; Higashida et al., 2007 and 2010). In humans, intranasal administration of OXT may promote trust (Kosfeld et al., 2005), generosity (Zak et al., 2007), gaze (Guastella et al., 2008a), mind-reading (Domes et al., 2007), and face recognition (Rimmele et al., 2009), as summarized in recent reviews (Heinrichs et al., 2009; Yamasue et al., 2009; Meyer-Lindenberg et al., 2011; Bartz et al., 2011). However, it has recently been noted that the effects of OXT are context- or situation-dependent (Bartz et al., 2011). Nasal administration of OXT can increase social contact without severe aversive effects (Yamasue et al., 2009; Ebstein et al., 2009: Munesue et al., 2010; MacDonald et al., 2011).

In voles and rodents, OXT is closely involved in social interactions, social recognition, pair bonding, and maternal behavior (Carter et al., 1992; Winslow and Insel, 2004; Insel and Fernald, 2004; Young and Wang, 2004; Young, 2007; Neumann, 2008; Donaldson and Young, 2008; Insel, 2010; Higashida et al., 2010). In addition, animal studies have shown that increased levels of OXT in the early postnatal period may affect behavior and last into adulthood (Young et al., 1997; Bridges, 2008; Carter et al., 
2009). Subcutaneous administration of low doses of OXT facilitates social recognition (Popik, 1992). Two types of mice with OXT or OXT receptor gene knockout $\left(\mathrm{Oxt}^{-/-}\right.$or Oxtr $^{-/}$) showed profound social amnesia (Nishimori et al., 1996; Ferguson et al., 2000; Takayanagi et al., 2005; Crawley et al., 2007; Macbeth et al., 2010; Sala et al., 2011), which was rescued by administration of OXT. These observations suggest that OXT plays an important role in social behavior by the stimulation of OXT receptor (OXTR) during brain development throughout the juvenile and adult stages (Ahern and Young, 2009; Carter et al., 2009; Insel, 2010; Bales et al., 2011) and suggest that dysfunction of OXT relate with generation of autism spectrum disorders (ASDs) in which social recognition and reciprocal social interaction are commonly disturbed (Frith and Frith, 2010).

\section{CD38 and ADP-ribosyl cyclase}

CD38 (Malavasi et al., 2008), a type II transmembrane protein (Lee, 2001; Higashida et al., 2007 and 2001a; Boittin et al., 2003; Guse, 2005; Ceni et al., 2006). ADP-ribosyl cyclase produces cyclic ADP-ribose (cADPR) from $\beta-\mathrm{NAD}^{+}$(Vitamin B3; Denu, 2005), which is an abundant substrate in the brain. CD38 was originally examined extensively in the field of immunology because it controls chronic leukocyte leukemia malignancy and is a marker of HIV infection in blood cells (Malavasi et al., 2008). The actual functions of CD38 and ADP-ribosyl cyclase in the nervous system were not clear until our recent report, in which we demonstrated that CD38 is required for social behavior in ICR mice (Jin et al., 2007). 
cADPR is a potential intracellular second messenger and a cofactor for $\mathrm{Ca}^{2+}$ mobilization through $\mathrm{Ca}^{2+}$-permeable channels $\left(\mathrm{Ca}^{2+}\right.$-induced $\mathrm{Ca}^{2+}$ release, CICR; Lee, 2001; Higashida et al., 2001a and b; Endo, 2009) from ryanodine-sensitive $\mathrm{Ca}^{2+}$ pools, resulting in increases in cytosolic free $\mathrm{Ca}^{2+}$ concentrations $\left(\left[\mathrm{Ca}^{2+}\right]_{\mathrm{i}}\right)$. Therefore, it is estimated that some cellular events, such as secretion or cell migration, depend on the formation of cADPR and binding of cADPR to type II ryanodine receptors in various tissues (Guse and Lee, 2008; Shawl et al., 2009; Malvasi et al., 2008). In addition, we have shown that CD38 is required for social behavior by regulating OXT secretion from the hypothalamus and pituitary in mice by decreased formation of cADPR and resulted in low CICR (Jin et al., 2007; Higashida et al., 2010; Salmina et al., 2010). Consistent with these results, we showed that social amnesia is induced by reducing OXT secretion in the hypothalamus (Jin et al., 2007; Higashida et al., 2010) when ADP-ribosyl cyclase is reduced by CD38 gene manipulation.

\section{Social amnesia in Cd38 knockout mice}

Mice lacking the $C d 38$ gene $\left(C d 38^{--}\right)$are viable and fertile, grow well, and gain weight (Kato et al., 1999; Liu et al., 2008) from the infant stage with the dam's milk to the adult stage after weaning onto solid food (Supplementary Figure S1 in Jin et al., 2007). Similarly, Nishimori et al. (1996) reported that mice lacking $O x t\left(O x t^{-/}\right)$are viable and fertile. Although $C d 38^{-/-}$mice showed no deficits in lactation/milk ejection, all $O x t^{-/}$ offspring die shortly after birth because of the dam's inability to nurse. However, postpartum injection of OXT into $O x t^{-/}$dams restores milk ejection and rescues the 
offspring (Nishimori et al., 1996). Similarly, Oxtr ${ }^{-/}$mice are viable and have no obvious defects in fertility or reproductive behavior. In addition, $\mathrm{Oxtr}^{-/}$dams exhibit normal parturition, but with defects in lactation and maternal nurturing (Takayanagi et al., 2005; Sala et al., 2011). These results indicate that in the OXT/CD38/OXTR signaling pathway, OXT and OXTR are not essential for normal parturition but are required for milk ejection, although CD38 is not critically involved in reproduction.

$C d 38^{-/-}$male pups on postnatal day 7 showed significantly higher levels of locomotor activity during the first $3 \mathrm{~min}$ after separation from the dam when they were examined individually in the grid-crossing test in an observation chamber (Liu et al., 2008). Both $C d 38^{-/-}$and $C d 38^{+/+}$pups emitted ultrasonic vocalization (USV) upon isolation. The USV calls per 2-min session were less frequent in $C d 38^{-/-}$pups than wild-type controls, with an average reduction of 38\% (Liu et al., 2008; Table 1 in Higashida et al., 2010) although the general properties of USV were similar in both genotypes. Locomotor activity was examined in the interacting plate by observing 4 pups simultaneously; $C d 38^{-/-}$pups exhibited less interaction than the controls (Liu et al., 2008), suggesting that $C d 38^{-/-}$pups retain the ability to interact socially to a lesser extent.

Young adult male mice investigate intruder females (Ferguson et al., 2000). $C d 38^{+/+}$males that experienced repeated pairings with the same conspecifics showed a significant decline in the time spent investigating the female upon subsequent presentations of the same animal (Fig. 1). This was not due to a loss of interest but the retained memory of the paired female, as suggested by Ferguson et al. (2000). The adult 
males did not need to investigate further because they recognized the paired female as their mate. In contrast, $C d 38^{-/}$males showed sustained high levels of investigation at each encounter with the same female and the same level of investigation (Jin et al., 2007). This abnormality in social memory found in $C d 38^{-/}$mice is due to the males' amnesia of conspecifics, which resembles a memory deficit observed in $O x t^{-/}$and Oxtr $^{-/}$mice (Ferguson et al., 2000; Takayanagi et al., 2005; Sala et al., 2011). Surprisingly, abnormal investigation behavior of $C d 38^{-/}$males was rescued immediately by OXT (less than $20 \mathrm{~min}$ after subcutaneous injection) and completely normal behavior was observed in $C d 38^{-/}$males infected via the third ventricle with lentivirus harboring human CD38, and thus re-expressing human CD38 locally in the hypothalamic area (Jin et al., 2007).

Normal dams retrieved the given 5 biological pups precisely and quickly (average latency, $43 \pm 3 \mathrm{~s}, n=10$ ) to the same small arena (nest) from the remote point in their home cages (Jin et al., 2007; Higashida et al., 2010), while $C d 38^{-/}$dams took a significantly longer time to begin retrieval (average latency, $76 \pm 8 \mathrm{~s} ; P<$ 0.01, $n=18$; Fig. 1) and moved around as if their interest was drawn to many things other than the pups (Lopatina et al., 2011). In addition, they often dropped the pups during retrieval as if they did not remember the way to the nest or its location, and this resulted in the pups becoming scattered throughout the cage. However, $C d 38^{-/-}$dams fed the pups in their nest $30 \mathrm{~min}$ or more after stressful isolation. The impairment of retrieval reported in $\mathrm{Oxtr}^{-/}$dams is similar to that in $\mathrm{Cd} 38^{-/-}$females. These results seem to indicate neglect-like abnormalities in the maternal nurturing behavior of postpartum 
$C d 38^{-/}$mice under stressful conditions, such as separation. Interestingly, this behavior was rescued immediately by subcutaneous injection of OXT or chronically in mice re-expressing human $\mathrm{CD} 38$ in the hypothalamic region due to a lentiviral vector (Jin et al., 2007) and was improved considerably with reproductive experience (Lopatina et al., 2011).

\section{Low oxytocin levels in mice}

In comparison with wild-type controls, $C d 38^{-/-}$mice have reduced OXT levels in the plasma and cerebrospinal fluid (CSF), but elevated levels in the hypothalamus and pituitary tissues (Fig. 2). Interestingly, plasma vasopressin levels were almost equivalent in both genotypes. These observations indicated that, although OXT is produced and packaged into the vesicles and stored in Herring bodies in the hypothalamic neurons and posterior pituitary nerve endings in $C d 38^{-/}$mice, it is not released into the brain and bloodstream. Indeed, the plasma and CSF levels of OXT in $C d 38^{-/}$mice could be normalized by a single subcutaneous injection of OXT, probably because OXT is passed to the brain (see Supplementary Fig. S7 of Jin et al., 2007). The similar path of OXT from the body to the brain in humans was reported (Born, 2002; Meyer-Lindenberg et al., 2011). Furthermore, a genetic approach involving the infusion of a virus carrying the human CD38 gene into the third ventricle of knockout mice resulted in normalization of the plasma and CSF OXT levels, thereby normalizing social memory (see Fig. 2 of Jin et al., 2007). These observations indicated that the mechanisms underlying social behavior require CD38-dependent OXT secretion (Fig. 
3).

Arginine vasopressin (AVP) release was relatively insensitive to the CD38 null mutation, suggesting that OXTnergic and AVPnergic neurons could be differentially controlled by CD38. It is not clear why CD38 mutation is insensitive to AVP neurons at this moment. Given the general role of cADPR in mobilizing $\mathrm{Ca}^{2+}$ from stores, other neurotransmitter, such as serotonin, or peptide systems could be affected. The detection of dopamine by microdialysis was not impaired in $C d 38^{-/-}$mice (Jin et al., 2007), demonstrating the specific involvement of CD38 in the OXT secretion pathway in the hypothalamic neurons.

\section{Contribution of TRPM2 channels to secretion in NG108-15 hybrid cells}

We measured $\left[\mathrm{Ca}^{2+}\right]_{\mathrm{i}}$ in neuroblastoma $\times$ glioma hybrid NG108-15 cells (Nirenberg et al., 1983) before and after stimulation with extracellularly applied $50 \mu \mathrm{M}$ cADPR. NG108-15 cells exhibited small but significant increases in $\left[\mathrm{Ca}^{2+}\right]_{\mathrm{i}}$ in response to $\mathrm{cADPR}$ at $35^{\circ} \mathrm{C}$. The average $\left[\mathrm{Ca}^{2+}\right]_{\mathrm{i}}$ after cADPR stimulation was $121 \%(n=4 ; P$ $<0.01$ ) of the pre-stimulation level (Amina et al., 2010). Surprisingly, NG108-15 cells showed significantly greater increases upon extracellular challenge with $50 \mu \mathrm{M}$ cADPR together with heating to $40^{\circ} \mathrm{C}$ (Fig. 4). The average peak level was $169 \%(n=5 ; P<$ $0.01)$, which was significantly larger than that at $35^{\circ} \mathrm{C}(P<0.001)$. These $\left[\mathrm{Ca}^{2+}\right]_{\mathrm{i}}$ amplifications in response to the combination of heat and cADPR were very similar to those observed in HEK-239 cells expressing TRPM2 channels (Togashi et al., 2008). 
NG108-15 hybrid cells showed TRPM2 mRNA expression as determined by RT-PCR.

Next, we examined cADPR-mediated changes in $\left[\mathrm{Ca}^{2+}\right]_{i}$ at $40^{\circ} \mathrm{C}$ in the absence of extracellular $\mathrm{Ca}^{2+}$. Little or no $\left[\mathrm{Ca}^{2+}\right]_{i}$ elevation was observed $(103 \%$ of the prestimulation level; $n=4$ ), strongly suggesting that $\mathrm{Ca}^{2+}$ influx, probably through non-selective cation TRPM2 channels, was triggered in response to the combination of cADPR and heat. The TRPM2 channel inhibitor, 2-aminoethoxydiphenyl borate (2-APB; Togashi et al., 2008), at a lower concentration $(30 \mu \mathrm{M})$ inhibited $\mathrm{Ca}^{2+}$ influx through TRPM2 channels activated by cADPR and heat. Therefore, we postulated that the OT could induce $\left[\mathrm{Ca}^{2+}\right]_{\mathrm{i}}$ elevation, elicited by cADPR in two ways (Amina et al., 2010): (1) $\mathrm{Ca}^{2+}$ release mediated through ryanodine receptors in a PKC-dependent manner and (2) $\mathrm{Ca}^{2+}$ influx through TRPM2 channels, as shown schematically in Fig. 5. It will be of interest to examine the extent to which TRPM2 channels can contribute to $\left[\mathrm{Ca}^{2+}\right]_{\mathrm{i}}$ increases in hypothalamic neurons or neurohypophyseal nerve endings, leading to effective OT release.

\section{Human CD38}

The neurobiological basis of ASDs remains to be elucidated. Given the role of CD38 in social recognition in OXT release, it is possible that CD38 plays a role in the etiology of ASDs. Here, we discuss studies of the association between CD38and autism, and present several ASD cases with long-term clinical treatment with OXT.

CD38 mRNA expression in the human brain was examined by quantitative RT-PCR using commercially available human brain mRNAs as templates; the highest 
level of CD38 was found in the hypothalamus (Munesue et al., 2010), as also reported in mice (Jin et al., 2007). The human CD38 protein was detected in the hypothalamus of American and Japanese postmortem human brains using anti-human CD38 antibody. These results suggest that CD38 plays a similar role in both human and mouse social behavior (Higashida et al., 2007; Salmina et al., 2010).

The human gene encoding CD38 is located on human chromosome 4 at position p15 (Nakagawa et al., 1995; Nata et al., 1997; Malavasi et al., 2008) and consists of 8 exons, spanning a genomic stretch of $70.5 \mathrm{~kb}$ (Fig. 6). In the first set of cohort studies, single nucleotide polymorphisms (SNPs) and mutation screening in 8 exons and their flanking introns were performed in 29 unrelated ASD subjects fulfilling the Diagnostic and Statistical Manual for Mental Disorders, Fourth edition (DSM-IV) and CASK criteria for ASD and in 201 non-clinical control subjects in the Kanazawa area, Japan. We detected 12 SNPs that have already been reported, along with 5 novel SNPs and mutations with or without amino acid alterations only in ASD subjects and/or control subjects.

\section{Intronic rs3796863 SNP of human CD38}

The rs379863 $(\mathrm{C}>\mathrm{A})$ SNP of CD38 in intron 7 showed a significant association with 147 American patients with high-functioning autism (HFA) $(P<$ 0.005), but not in 182 Japanese HFA patients $(P=0.23)$ (Munesue et al., 20010), which is ethnically specific. The reason why this association was found in only American, but not Japanese, HFA patients is not clear. This is one of few common 
variants that may contribute to the genetic susceptibility to HFA (Nakamura et al., 2008; Wermter et al., 2010). Based on our results of SNP and haplotype transmission disequilibrium test analyses, the $\mathrm{C}$ allele of rs3796863 in CD38 may be considered a protective allele (Fig. 6) and the A allele may be a risk allele in American HFA cases (Fig. 4 in Munesue et al., 2010). These results were partially reproduction by Lerer et al. in 170 Israeli ASD patients (2010). They showed that rs3796863 has a significant association with low-functioning autism, but not necessarily with HFA.

This variant is common with an allele frequency of about 0.3 . Very recently, common variants on chromosome 5p14.1, together with 6 meaningful variants between neural cadherin 10 and 9, have been reported to be associated with ASD (Wang et al., 2009). As rs3796863 is an intronic SNP, the functional importance of this SNP remained to be examined. Lerer et al. (2010) suggested that this allele may contribute to the decreased expression of CD38 in ASD subjects based on analysis of immortalized lymphoid cells from ASD subjects and their non-idiopathic parents. In addition, they suggested that retinoids may be have therapeutic potential to increase CD38 expression in ASD subjects, as shown in Fig. 7 (Riebold et al., 2011; Ebstein, 2011). Very recently it was reported that CD38 is closely related to disfunction of OXT secretion in ASD patients (Kiss et al., 2011). Therefore, it is possible that CD38 regulates OXT release in the brains of normal and ASD subjects (Munesue et al., 2010).

\section{Exonic rs1800161 SNP of human CD38}

Among the SNPs in exons shown in Fig. 6, we focused on the C4693T 
mutation in exon 3 (rs1800561) that leads to an arginine (R)-to-tryptophan (W) substitution at amino acid $140(\mathrm{R} 140 \mathrm{~W})$. Interestingly, R140 is located in the flexible loop (amino acid residues 137 - 141) at the midpoint of the $\mathrm{N}$ - and C-terminal domains between 2 helical domains ( $\alpha \mathrm{a} 4$ and $\alpha \mathrm{a} 5$ ), and is the pivot of the hinge region connecting two regions of the L-shaped molecule (Munesue et al., 2010). Therefore, the R140W mutation causes significant modifications and damage to the predicted protein structure in comparison with the human wild-type (R140R) CD38 (see Fig. 7 of Munesue et al., 2010). It has been reported that the mutant R140W-CD38 showed one-third of the ADP-ribosyl cyclase activity of R140R CD38 when expressed in CHO cells (Yagui et al., 1998). Shown as the in vivo effect, social amnesia was not rescued by the local expression of human R140W-CD38 by lentivirus infection in the hypothalamus of $C d 38$ knockout mice (Fig. 2 of Jin et al., 2007).

Heterozygosity for 140R/W (C4693T) was found in 3 male subjects (2 autistic and 1 Asperger) among 29 ASD subjects examined (23 males and 6 females; mean age, $22.8 \pm 7.6$ years; allele frequency, 0.052). Two females and 1 male among 315 healthy unscreened controls were positive for the heterozygous mutation, representing an allele frequency of 0.0048 (Munesue et al., 2010). This frequency was 10.8-fold lower than that in the ASD patient group from the same residential area $(P<0.029)$.

This SNP is relatively frequent in the Asian population (see Munesue et al., 2010), but was very infrequent in 551 white (non-Hispanic and non-Latino) subjects in Autism Genetic Resource Exchange (AGRE) samples, although recently we found one heterozygous ASD patient with this SNP. These results suggest that the mutation is 
carried mostly by the general Asian population.

Next, we examined whether the R140W allele co-segregated with ASD and ASD-related traits in 3 proband families in the above group. Twenty-five members of the 3 kindred families were available for detailed clinical and genetic analyses. The 4693 C-to-T SNP was found in all proband fathers of the 3 families and in the brothers belonging to 2 families. The mutation is apparently an autosomal dominant trait. We identified 18 carriers in 29 family members who agreed to be tested. In all cases, the mutation was heterozygous (allele frequency $=0.32$ ). The mutant allele was indeed transcribed in the subjects tested (Munesue et al., 2010; Higashida et al., 2010).

The probands' younger (Fig. 8C) and older (Fig. 8D) brothers showed clinical features consistent with ASD. Two fathers in their 50s and another father in his 70s were diagnosed with ASD traits. Most other adults over 50 years of age in these pedigrees had not been clinically diagnosed with ASD or other psychiatric diseases and adapted well to acquire daily living skills. Two female cousins with the R140W allele did not show ASD traits. These data suggest that this R140W allele is necessary but not sufficient for ASD.

Furthermore, we evaluated these subjects using the Japanese version of the Autism Spectrum Quotient behavioral test (AQ; Munesue et al., 2008), in which older subjects self-reported behaviors in their 20s. AQ scores in 2 young male carriers in the families fulfilled the criteria (cut-off point of 28) for ASD, indicating that such carriers will manifest ASD. These clinical and self-describing evaluations suggest that this mutation is important in determining ASD or phenotypes of ASD-related traits. 


\section{Oxytocin and vasopressin levels in control and ASD subjects}

Given these results, we obtained serum samples from the kindred to further study the connection between the human CD38 mutation and plasma OXT or arginine vasopressin (AVP) levels, as slow levels of OXT have been reported in autistic children (Modahl et al., 1998). Plasma OXT levels in the R140W carriers $(161.3 \pm 26.5 \mathrm{pg} / \mathrm{ml}$; $n=12)$ were lower than those in the kindred non-carriers $(345.8 \pm 61.3 \mathrm{pg} / \mathrm{ml} ; n$ $=10 ; P<0.01)($ Fig. 8). The OXT levels of 3 probands and 2 young carriers were compared with those of ASD subjects lacking the W140 mutation: the levels of five W140 carriers $(79.2 \pm 16.6 \mathrm{pg} / \mathrm{ml} ; n=5$; Munesue et al., 2010) were lower than those of ASD subjects lacking the mutation $(147.7 \pm 15.0 \mathrm{pg} / \mathrm{ml} ; P<0.01 ; n=$ 26). Furthermore, the OXT levels of ASD probands with the W140 allele were significantly lower than those in 101 control adults $(198.2 \pm 24.7 \mathrm{pg} / \mathrm{ml} ; P<0.01)$. The OXT levels were not lower in control subjects with than in those without the W140 allele (Fig. 8E).

Furthermore, there were no differences in AVP levels of the CD38 SNP carriers and non-carriers in the pedigrees (data not shown). These observations were consistent with the working hypothesis that CD38 is related only to OXT release but not to AVP release.

\section{Progression and regression by nasal oxytocin administration}

In June 2008, we were informed by the mother of one (Fig. 8D) of three 
probands, a 23-year-old man with autism, that she had begun giving her son OXT (one puff per nostril every morning and evening; 16 IU/day, $40 \mathrm{IU} / \mathrm{ml}$ Syntocinon spray; Novartis). As this patient had the C4693T (rs1800561) polymorphism and plasma OXT levels were lower than control adult males (Fig. 8A and B), his parents decided to personally provide OXT. His behavioral symptoms showed considerable progress with the regular use of OXT for 36 months (Table 1). At the periodic clinical checkup, he made good eye contact with the one of authors and even had a friendly appearance with a smile and improved gaze. He could answer yes/no questions (i.e., "Did you sleep well last night?") and even some alternative questions such as "Is it fair or cloudy today?" with enhanced communication. His intelligence quotient (IQ) was measured successfully in January 2009 (IQ $=21$ ) using the Japanese version of the Stanford-Binet Intelligence Scale, although IQ could not be measure before OXT treatment. When he stopped taking OXT for three months, his behavior dropped to the original low level and again his IQ could not be measured. However, renewing the OXT intake of two puffs every morning was accompanied by recovery.

\section{Personal and relatively long-term use of oxytocin in ASD subjects}

As we experienced some effectiveness of OXT in the above patient with the R140W SNP, we reconsidered the use of OXT as a possible treatment for ASD. Psychopharmacological interventions have been conducted in the treatment of ASD subjects. However, all agents examined to date showed either limited or no

effectiveness in ameliorating ASD symptoms. For example, risperidone, a 
second-generation antipsychotic, was suggested to be effective in managing irritability such as tantrums, aggression, and self-injurious behavior in ASD subjects, but not social withdrawal and inappropriate speech (McCracken et al., 2002). Although selective serotonin reuptake inhibitors (SSRI) are the most frequently used medications for ASD subjects (Esbensen et al., 2009), citalopram, an SSRI, showed little or no efficacy in treating social withdrawal, inappropriate speech, and repetitive behavior in a well-designed controlled study (King et al., 2009). Notably, conventional medications showed no beneficial effects on impairment of social interaction such as reciprocal communication, which are core symptoms in ASD subjects. Although OXT is only approved for induction of labor by intravenous injection in most countries, it is freely available as a nasal spray. Thus, ASD individuals may use the OXT nasal spray to reduce the various constraints in their daily life (MacDonald and Macdonald, 2010; Kuehn, 2011). To date, no randomized controlled trials of OXT have been published regarding its use in the treatment of ASD subjects.

Intellectual levels of ASD range from profound disability to excellent. ASD subjects with severe or profound mental deficiency are heavy burdens on their caregivers from infancy to adulthood because of their troublesome behaviors, such as lack of communication and effective contact, hyperkinesis, temper tantrums, self-injury, screaming, incomprehension of social common sense, and aggression (Lecavalier et al., 2006). As we have already noted that ASD subjects receive some benefits from the personal use of the OXT nasal spray (Munesue et al., 2010), we have received many inquiries by caregivers of ASD individuals regarding OXT use, most of whom suffered 
from severe and profound mental deficiencies.

Twenty-seven ASD individuals participated in our ASD genetic study, which was approved by Kanazawa University Medical Committee of Ethics. Written informed consent was obtained from the parents of all subjects prior to enrollment in the study. Three subjects who later began to personally take OXT through intranasal administration (Table 1) were diagnosed as having an autistic disorder based on DSM-IV (American Psychiatric Association) and using the Diagnostic Interview for Social and Communication Disorders (Wing et al., 2002). Their intelligence levels could not be measured because of lack of cooperation, and they were estimated to have severe or profound mental disabilities. One patient (case 2 in Table 1), who had been treated by one of the authors for epilepsy, personally used the OXT nasal spray for 1 year. Although he did not participate in our genetic study, he was diagnosed with autism and severe mental retardation in infancy by a psychiatrist.

In summary, 6 male adolescents and adults with ASD were nasally administered OXT for periods between 4 months and 2 years based on their caregiver's personal decision (Table 1). All of them suffered from an estimated severe or profound impairment of intelligence. Previously prescribed medications appeared ineffective according to their caregivers, except for antiepileptic medications, which were helpful in treating the epilepsy in case 6. The caregiver's global impressions of the effectiveness of OXT were "much improved" in 3 subjects, "minimally improved" in 1 subjects, and "no change" in 2 subjects. Appreciable adverse effects have not been reported by their caregivers. These findings were in accordance with those reported by 
MacDonald et al. (2011). These observations from personal use of OXT are discussed below.

First, eye-to-eye gaze improved in 3 subjects, and the ability to converse developed in another 3 subjects, as expected from the results in healthy subjects (Guastella et al., 2008a and b; Ditzen et al., 2009) and autistic patients (Hollander et al., 2007). Despite the impairment of intelligence, 4 of 6 subjects appeared to be able to considerably establish reciprocal social interactions. Although observer bias and inherent development should be taken into consideration as causes of improvements, caregivers were more comfortable with ASD subjects after they began taking OXT. However, 3 subjects were in late adolescence; thus, these improvements could be regarded as due to inherent development. However, as one subject was near middle age, his improvement was unlikely to have been due to such inherent development.

Second, according to their caregivers, irritability or aggression decreased or even disappeared in 3 subjects after commencement of OXT treatment. One patient, who had strongly persisted in buying particular goods at a supermarket whenever he went with his family has now complied with his caregiver's instructions to not adhere to such restricted patterns of activities after taking OXT. These explicit changes are not interpreted as indicative of observation bias. Third, it remains unclear why 2 subjects did not show behavioral improvements with OXT administration. Finally, the results of this case series indicated that OXT may be an effective treatment for ASD subjects, and it highlights the urgent need for randomized controlled trials. 


\section{Conclusion}

Recent genetic and biological studies indicated that defects in OXT signaling confer vulnerability to ASD. CD38 SNPs appear to provide a genetic basis for cases of ASD that arise from the disruption of OXT signaling. Furthermore, although the R140W mutation was found in 1 of 445 American AGRE samples, the association study with Tag SNPs showed 1 SNP (rs3796863) in CD38 that was positively correlated with American HFA or Israeli ASD patients. Therefore, it is possible that CD38 mutations may provide a genetic basis for such cases of ASD, and this was replicated recently in two studies (Kiss et al., 2011; Feldman et al., 2011). CD38 SNPs may cause lower OXT levels in ASD subjects. However, we do not know whether clinically unaffected carriers with this mutant allele in families and general populations may be influenced by compensatory factors for ASD (Fig. 9). To our knowledge, this is the first report to show the therapeutic effects of OXT on the social deficits in a limited number of ASD patients in terms of long-term benefits and real-life situations. However, its efficacy was based on self-judgment, including parental reports and doctor's judgment determined from clinical interviews. Thus, the effects of OXT should be tested by clear objective scales in future studies. Despite the limitation of the absence of control trials, observations of subjects in our clinical office and in their homes by their parents, as noted in the reports, are potentially clinically relevant in evaluating the contribution of OXT to the core behavioral domains (social and communication behaviors) of ASD subjects. In addition, aggression and irritability due probably to anxiety frequently observed in ASD as typical symptoms in the adolescent period were reduced. 


\section{References}

Ahern, T.H., Young, L.J., 2009. The impact of early life family structure on adult social attachment, alloparental behavior, and the neuropeptide systems regulating affiliative behaviors in the monogamous prairie vole (microtus ochrogaster). Front. Behav. Neurosci. 3, 17.

Amina, S., Hashii, M., Ma, W.J., Yokoyama, S., Lopatina, O., Liu, H.X., Islam, M.S., Higashida, H., 2010. Intracellular calcium elevation induced by extracellular application of cyclic-ADP-ribose or oxytocin is temperature-sensitive in rodent NG108-15 neuronal cells with or without exogenous expression of human oxytocin receptors. J. Neuroendocrinol. 22, 460-466.

Anitha, A., Nakamura, K., Yamada, K., Suda, S., Thanseem, I., Tsujii, M., Iwayama, Y., Hattori, E., Toyota, T., Miyachi, T., Iwata, Y., Suzuki, K., Matsuzaki, H., Kawai, M., Sekine, Y., Tsuchiya, K., Sugihara, G., Ouchi, Y., Sugiyama, T., Koizumi, K., Higashida, H., Takei, N., Yoshikawa, T., Mori, N., 2008. Genetic analyses of roundabout (ROBO) axon guidance receptors in autism. Am. J. Med. Genet. B Neuropsychiatr. Genet. 147B, 1019-1027.

Bales, K.L., Boone, E., Epperson, P., Hoffman, G., Carter, C.S., 2011. Are behavioral effects of early experience mediated by oxytocin? Front. Psychiatry. 2: 24.

Bartz, J.A., Zaki, J., Bolger, N., Ochsner, K.N., 2011. Social effects of oxytocin in humans: context and person matter. Trends Cogn. Sci. 15, 301-309.

Boittin, F.X., Dipp, M., Kinnear, N.P., Galione, A., and Evans, A.M., 2003. Vasodilation by the calcium-mobilizing messenger cyclic ADP-ribose. J. Biol. Chem. 278, 9602-9608.

Born, J., Lange, T., Kern, W., McGregor, GP., Bickel, U., Fehm H.L., 2002. Sniffing neuropeptides: a transnasal approach to the human brain Nature Neurosci. 5, 514-516

Bridges, R.S., 2008. Parenting and the brain: an overview. in Neurobiology of the Parental Brain. ed. Bridges, R.S. Academic Press, Elsevier, MA, pp xxix-xxxvi.

Brownstein, M.J., Russell, J.T., Gainer, H., 1980. Synthesis, transport, and release of posterior pituitary hormones. Science 207, 373-378.

Carter, C.S., 2003. Developmental consequences of oxytocin. Physiol. Behav. 79, 383-397.

Carter, C.S., Boone, E.M., Pournajafi-Nazarloo, H., Bales, K.L., 2009. Consequences of 
early experiences and exposure to oxytocin and vasopressin are sexually dimorphic. Dev. Neurosci. 31, 332-341.

Carter, C.S., Williams, J.R., Witt, D.M., Insel, T.R., 1992. Oxytocin and social bonding. Ann. N. Y. Acad. Sci. 652, 204-211

Ceni, C., Pochon, N., Villaz, M., Muller-Steffner, H., Schuber, F., Baratier, J., De Waard, M., Ronjat, M., Moutin, M.J., 2006. The CD38-independent ADP-ribosyl cyclase from mouse brain synaptosomes: a comparative study of neonate and adult brain. Biochem J. 395, 417-426.

Crawley, J.N., Chen, T., Puri, A., Washburn, R., Sullivan, T.L., Hill, J.M., Young, N.B., Nadler, J.J., Moy, S.S., Young, L.J., Caldwell, H.K., Young, W.S., 2007. Social approach behaviors in oxytocin knockout mice: comparison of two independent lines tested in different laboratory environments. Neuropeptides 41, 145-163.

Denu, J.M., 2005. Vitamin B3 and sirtuin function. Trends. Biochem. Sci. 30, 479-483.

Ditzen, B., Schaer, M., Gabriel, B., Bodenmann, G., Ehlert, U., Heinrichs, M., 2009. Intranasal oxytocin increases positive communication and reduces cortisol levels during couple conflict. Biol. Psychiatry 65, 728-731.

Domes, G., Heinrichs, M., Michel, A., Berger, C., Herpertz, S.C., 2007. Oxytocin improves "mind-reading" in humans. Biol. Psychiatry 61, 731-733.

Donaldson, Z.R., Young, L.J., 2008. Oxytocin, vasopressin, and the neurogenetics of sociality. Science 322, 900-904.

Ebstein, R.P., Israel, S., Lerer, E., Uzefovsky, F., Shalev, I., Gritsenko, I., Riebold, M., Salomon, S., Yirmiya, N., 2009. Arginine vasopressin and oxytocin modulate human social behavior. Ann. N. Y. Acad. Sci. 1167, 87-102.

Ebstein, R.P., Mankuta, D., Yirmiya, N., Malavasi, F., 2011. Are retinoids potential therapeutic agents in disorders of social cognition including autism? FEBS Lett. 585, 1529-1536.

Endo, M., 2009. Calcium-induced calcium release in skeletal muscle. Physiol. Rev. 89, 1153-1176.

Esbensen, A.J., Greenberg, J.S., Seltzer, M.M., Aman, M.G., 2009. A longitudinal investigation of psychotropic and non-psychotropic medication use among adolescents and adults with autism spectrum disorders. J. Autism Dev. Disord, 39, 1339-1349.

Feldman, R., 2011. Oxytocin and affiliation in humans: Becoming a parent and falling 
in love. $9^{\text {th }}$ World Congress on Neurohypophysial Hormones. Abstract p. 33.

Ferguson, J.N., Young, L.J., Hearn, E.F., Matzuk, M.M., Insel, T.R., Winslow, J.T., 2000. Social amnesia in mice lacking the oxytocin gene. Nature Genet. 25, 284-288.

Feldman, R., 2011. Oxytocin and affiliation in human: Becoming a parent and falling in love. Abstract of $9^{\text {th }}$ World Congress on Neurohypophysial Hormones, p23.

Frith, C.D., Frith, U., 2010. Mechanisms of Social Cognition. Annu. Rev. Psychol. [Epub ahead of print].

Geschwind, D.H, Sowinski, J., Lord, C., Iversen, P., Shestack, J., Jones, P., Ducat, L., Spence, S.J.; AGRE Steering Committee., 2001. The autism genetic resource exchange: a resource for the study of autism and related neuropsychiatric conditions. Am. J. Hum. Genet. 69, 463-466.

Guastella, A.J., Einfeld, S.L., Gray, K.M., Rinehart, N.J., Tonge, B.J., Lambert, T.J., Hickie, I.B., 2010. Intranasal oxytocin improves emotion recognition for youth with autism spectrum disorders. Biol. Psychiatry. 67, 692-694.

Guastella, A.J., Mitchell, P.B., Dadds, M.R., 2008a. Oxytocin increases gaze to the eye region of human faces. Biol. Psychiatry 63, 3-5.

Guastella, A.J., Mitchell, P.B., Mathews, F., 2008b. Oxytocin enhances the encoding of positive social memories in humans. Biol. Psychiatry 64, 256-258.

Guse, A.H., 2005. Second messenger function and the structure-activity relationship of cyclic adenosine diphosphoribose (cADPR). FEBS J. 272, 4590-4597.

Guse, A.H., Lee, H.C., 2008. NAADP: a universal Ca2+ trigger. Sci. Signal. 1, re10.

Heinrichs, M., von Dawans, B., Domes, G., 2009. Oxytocin, vasopressin, and human social behavior. Front. Neuroendocrinol. 30, 548-557.

Higashida, H., Hashii, M., Yokoyama, S., Hoshi, N., Asai, K., Kato, T., 2001b. Cyclic ADP-ribose as a potential second messenger for neuronal $\mathrm{Ca} 2+$ signaling. $\mathrm{J}$. Neurochem. 76, 321-331.

Heinrichs, M., von Dawans, B., Domes, G., 2009. Oxytocin, vasopressin, and human social behavior. Front. Neuroendocrinol. 30, 548-557.

Higashida, H., Hashii, M., Yokoyama, S., Hoshi, N., Chen, X.L., Egorova, A., Noda, M., Zhang, J.S., 2001a. Cyclic ADP-ribose as a second messenger revisited from a new aspect of signal transduction from receptors to ADP-ribosyl cyclase. Pharmacol. Ther. 90, 283-296. 
Higashida, H., Lopatina, O., Yoshihara, T., Pichugina, Y.A., Soumarokov, A.A., Munesue, T., Minabe, Y., Kikuchi, M., Ono, Y., Korshunova, N., Salmina, A.B., 2010. Oxytocin signal and social behaviour: comparison among adult and infant oxytocin, oxytocin receptor and CD38 gene knockout mice. J. Neuroendocrinol. 22, 373-379.

Higashida, H., Salmina, A.B., Olovyannikova, R.Y., Hashii, M., Yokoyama, S., Koizumi, K., Jin, D., Liu, H.X., Lopatina, O., Amina, S., Islam, M.S., Huang, J.J., Noda, M., 2007. Cyclic ADP-ribose as a universal calcium signal molecule in the nervous system. Neurochem. Int. 51, 192-199.

Hollander, E., Bartz ,J., Chaplin, W., Phillips, A., Sumner, J., Soorya, L., Anagnostou, E., Wasserman, S., 2007. Oxytocin increases retention of social cognition in autism. Biol. Psychiatry. 61, 498-503.

Insel, T.R., 2010. The challenge of translation in social neuroscience: a review of oxytocin, vasopressin, and affiliative behavior. Neuron 65, 768-79.

Insel, T.R., Fernald, R.D., 2004. How the brain processes social information: searching for the social brain. Annu. Rev. Neurosci. 27, 697-722.

Jin, D., Liu, H.X., Hirai, H., Torashima, T., Nagai, T., Lopatina, O., Shnayder, N.A., Yamada, K., Noda, M., Seike, T., Fujita, K., Takasawa, S., Yokoyama, S., Koizumi, K., Shiraishi, Y., Tanaka, S., Hashii, M., Yoshihara, T., Higashida, K., Islam, M.S., Yamada, N., Hayashi, K., Noguchi, N., Kato, I., Okamoto, H., Matsushima, A., Salmina, A., Munesue, T., Shimizu, N., Mochida, S., Asano, M., Higashida, H., 2007. CD38 is critical for social behaviour by regulating oxytocin secretion. Nature 446, 41-45.

Kato, I., Yamamoto, Y., Fujimura, M., Noguchi, N., Takasawa, S., Okamoto, H., 1999. CD38 disruption impairs glucose-induced increases in cyclic ADP-ribose, $\left[\mathrm{Ca}^{2+}\right]_{\mathrm{i}}$, and insulin secretion. J. Biol. Chem. 274, 1869-1872.

King, B.H., Hollander, E., Sikich, L., McCracken, J.T., Scahill, L., Bregman, J.D., Donnelly, C.L., Anagnostou, E., Dukes, K., Sullivan, L., Hirtz, D., Wagner, A. Ritz, L., 2009. STAART Psychopharmacology Network: Lack of efficacy of citalopram in children with autism spectrum disorders and high levels of repetitive behavior: citalopram ineffective in children with autism. Arch. Gen. Psychiatry, 66, 583-590.

Kosfeld, M., Heinrichs, M., Zak, P.J., Fischbacher, U., Fehr, E., 2005. Oxytocin 
increases trust in humans. Nature 435, 673-676.

Kuehn, B.M., 2011. Scientists probe oxytocin therapy for social deficits in autism, schizophrenia. JAMA, 305, 659-661.

Lecavalier, L., 2006. Behavioral and emotional problems in young people with pervasive developmental disorders: relative prevalence, effects of subject characteristics, and empirical classification. J. Autism. Dev. Disord. 36, 1101-1114.

Lee, H.C., 2001. Physiological functions of cyclic ADP-ribose and NAADP as calcium messengers. Ann. Rev. Pharmacol. Toxicol. 41, 317-345.

Lerer, E., Levi, S., Israel, S., Yaari, M., Nemanov, L., Mankuta, D., Nurit, Y., Ebstein, R.P., 2010. Low CD38 expression in lymphoblastoid cells and haplotypes are both associated with autism in a family-based study. Autism Res. 3, 293-302.

Lim, M.M., Young, L.J., 2006. Neuropeptidergic regulation of affiliative behavior and social bonding in animals. Horm. Behav. 50, 506-517.

Liu, H.X., Lopatina, O., Higashida, C., Tsuji, T., Kato, I., Takasawa, S., Okamoto, H., Yokoyama, S., Higashida, H., 2008. Locomotor activity, ultrasonic vocalization and oxytocin levels in infant CD38 knockout mice. Neurosci. Lett. 448, 67-70.

Lopatina, O., Inzhutova, A., Pichugina, Y.A., Okamoto, H., Salmina, A.B., Higashida, H., 2011. Reproductive experience affects parental retrieval behaviour associated with increased plasma oxytocin levels in wild-type and Cd38-knockout mice. J. Neuroendocrinol. doi: 10.1111.

Lopatina, O., Liu, H.X., Amina, S., Hashii, M., Higashida, H., 2010. Oxytocin-induced elevation of ADP-ribosyl cyclase activity, cyclic ADP-ribose or $\mathrm{Ca}^{2+}$ concentrations is involved in autoregulation of oxytocin secretion in the hypothalamus and posterior pituitary in male mice. Neuropharmacology. 58, $50-55$.

Ludwig, M., Leng, G., 2006. Dendritic peptide release and peptide-dependent behaviours. Nat. Rev. Neurosci. 7, 126-136.

Macbeth, A.H., Stepp, J.E., Lee, H.J., Young, W.S. 3rd, Caldwell, H.K., 2010. Normal maternal behavior, but increased pup mortality, in conditional oxytocin receptor knockout females. Behav. Neurosci. 124, 677-685.

MacDonald, E., Dadds, M.R., Brennan, J.L., Williams, K., Levy, F., Cauchi A.J., 2011. A review of safety, side-effects and subjective reactions to intranasal oxytocin in 
human research. Psychoneuroendocrinology in press.

MacDonald, K., MacDonald, T.M., 2010. The peptide that binds: a systematic review of oxytocin and its prosocial effects in humans. Harv. Rev. Psychiatry. 18, 1-21.

Malavasi, F., Deaglio, S., Funaro, A., Ferrero, E., Horenstein, A.L., Ortolan, E., Vaisitti, T., Aydin, S., 2008. Evolution and function of the ADP ribosyl cyclase/CD38 gene family in physiology and pathology. Physiol. Rev. 88, 841-886.

Malek, A., Blann, E., Mattison, D.R., 1996. Human placental transport of oxytocin. J. Matern. Fetal Med. 5, 245-255.

McCracken, J.T., McGough, J., Shah, B., Cronin, P., Hong, D., Aman, M.G., Arnold, L.E., Lindsay, R., Nash, P., Hollway, J., McDougle, C.J., Posey, D., Swiezy, N., Kohn, A., Scahil,1 L., Martin, A., Koenig, K., Volkmar, F.,, Carroll D., Lancor, A., Tierney, E., Ghuman, J., Gonzalez, N.M., Grados, M., Vitiello, B., Ritz, L., Davie,s M., Robinson, J. McMahon, D., 2002. Risperidone in children with autism and serious behavioral problems. N. Engl. J Med, 347, 314-321.

Meyer-Lindenberg, A., Domes, G., Kirsch, P., Heinrichs, M., 2011. Oxytocin and vasopressin in the human brain: social neuropeptides for translational medicine. Nat. Rev. Neurosci. 12, 524-538.

Popik, P., Vetulani, J., van Ree, J.M., 1992. Low doses of oxytocin facilitate social recognition in rats. Psychopharmacology (Berl). 106, 71-74.

Modahl, C., Green, L., Fein, D., Morris, M., Waterhouse, L., Feinstein, C., Levin, H., 1998. Plasma oxytocin levels in autistic children. Biol. Psychiatry. 43, 270-277.

Munesue, T., Ono, Y., Mutoh, K., Shimoda, K., Nakatani, H., Kikuchi, M., 2008. High prevalence of bipolar disorder comorbidity in adolescents and young adults with high-functioning autism spectrum disorder: a preliminary study of 44 outpatients. J. Affect. Disord. 111, 170-175.

Munesue, T., Yokoyama, S., Nakamura, K., Anitha, A., Yamada, K., Hayashi, K., Asaka, T., Liu, H.X., Jin, D., Koizum,i K., Islam, M.S., Huang, J.J., Ma, W.J., Kim, U.H., Kim, S.J., Park, K., Kim, D., Kikuchi, M., Ono, Y., Nakatani, H., Suda, S., Miyachi, T., Hirai, H., Salmina, A., Pichugina, Y.A., Soumarokov, A.A., Takei, N., Mori, N., Tsujii, M., Sugiyama, T., Yagi, K., Yamagishi, M., Sasaki, T., Yamasue, H., Kato, N., Hashimoto, R., Taniike, M., Hayashi, Y., Hamada, J., Suzuki, S., Ooi, 
A., Noda, M., Kamiyama, Y., Kido, M.A., Lopatina, O., Hashii, M., Amina, S., Malavasi, F., Huang, E.J., Zhang, J., Shimizu, N., Yoshikawa, T., Matsushima, A., Minabe, Y., Higashida, H., 2010. Two genetic variants of CD38 in subjects with autism spectrum disorder and controls. Neurosci. Res. 67, 181-191.

Nakagawara, K., Mori, M., Takasawa, S., Nata, K., Takamura, T., Berlova, A., Tohgo, A., Karasawa, T., Yonekura, H., Takeuchi, T., Okamoto, H. 1995. Assignment of CD38, the gene encoding human leukocyte antigen CD38 (ADP-ribosyl cyclase/cyclic ADP-ribose hydrolase), to chromosome 4p15. Cytogenet. Cell Genet. 69, 38-39.

Nakamura, K., Anitha, A., Yamada, K., Tsujii, M., Iwayama, Y., Hattori, E., Toyota, T., Suda, S., Takei, N., Iwata, Y., Suzuki, K., Matsuzaki, H., Kawai, M., Sekine, Y., Tsuchiya, K.J., Sugihara, G., Ouchi, Y., Sugiyama, T., Yoshikawa, T., Mori, N., 2008. Genetic and expression analyses reveal elevated expression of syntaxin $1 \mathrm{~A}$ (STX1A) in high functioning autism. Int. J. Neuropsychopharmacol. 11, 1073-1084.

Nata, K., Takamura, T., Karasawa, T., Kumagai, T., Hashioka, W., Tohgo, A., Yonekura, H., Takasawa, S., Nakamura, S., Okamoto, H., 1997. Human gene encoding CD38 (ADP-ribosyl cyclase/cyclic ADP-ribose hydrolase): organization, nucleotide sequence and alternative splicing. Gene 186, 285-292.

Neumann, I.D., 2008. Brain oxytocin: a key regulator of emotional and social behaviours in both females and males. J. Neuroendocrinol. 20, 858-865.

Neumann, I., Douglas, A.J., Pittman, Q.J., Russell, J.A., Landgraf, R., 1996. Oxytocin released within the supraoptic nucleus of the rat brain by positive feedback action is involved in parturition-related events. J. Neuroendocrinol. 8, 227-233.

Neumann, I., Koehler, E., Landgraf, R., Summy-Long, J., 1994. An oxytocin receptor antagonist infused into the supraoptic nucleus attenuates intranuclear and peripheral release of oxytocin during suckling in conscious rats. Endocrinol. 134, 141-148.

Nirenberg, M., Wilson, S., Higashida, H., Rotter, A., Krueger, K., Busis, N., Ray, R., Kenimer, J.G., Adler, M., 1983. Modulation of synapse formation by cyclic adenosine monophosphate. Science. 222, 794-799.

Nishimori, K., Young, L.J., Guo, Q., Wang, Z., Insel, T.R., Matzuk, M.M., 1996. Oxytocin is required for nursing but is not essential for parturition or reproductive 
behavior. Proc. Natl. Acad. Sci. U S A. 93, 11699-11704.

Riebold, M., Mankuta, D., Lerer, E., Israel, S., Zhong, S., Nemanov, L., Monakhov, M.V., Levi, S., Yirmiya, N., Yaari, M., Malavasi, F., Ebstein, R.P., 2011. All-trans-Retinoic-Acid (ATRA) upregulates reduced CD38 transcription in lymphoblastoid cell lines from autism spectrum disorder. Mol, Med. Apr 25.

Rimmele, U., Hediger, K., Heinrichs, M., Klaver, P., 2009. Oxytocin makes a face in memory familiar. J. Neurosci. 29, 38-42.

Ross, H.E., Young, L.J., 2009. Oxytocin and the neural mechanisms regulating social cognition and affiliative behavior. Front. Neuroendocrinol. 30, 534-547.

Russell, J.A., Leng, G., Douglas, A.J., 2003. The magnocellularoxytocin system, the fount of maternity: adaptations inpregnancy. Front. Neuroendocrinol. 24, 27-61.

Sala, M., Braida, D., Lentini, D., Busnelli, M., Bulgheron,i E., Capurro, V., Finardi, A., Donzelli, A., Pattini, L., Rubino, T., Parolaro, D., Nishimori, K., Parenti, M., Chini, B., 2011. Pharmacologic rescue of impaired cognitive flexibility, social deficits, increased aggression, and seizure susceptibility in oxytocin receptor null mice: a neurobehavioral model of autism. Biol. Psychiatry 69, 875-882.

Salmina, A.B., Lopatina, O., Ekimova, M.V., Mikhutkina, S.V., Higashida, H., 2010. CD38/cyclic ADP-ribose system: a new player for oxytocin secretion and regulation of social behaviour. J. Neuroendocrinol. 22, 380-392.

Shawl, A.I., Park, K.H., Kim, U.H., 2009. Insulin receptor signaling for the proliferation of pancreatic $\beta$-cells: involvement of $\mathrm{Ca} 2+$ second messengers, IP3, NAADP and cADPR. Islets 1, 216-223.

Skuse, D.H., Gallagher, L., 2000. Dopaminergic-neuropeptide interactions in the social brain. Trends Cognitive Sci. 13, 27-35.

Takayanagi, Y., Yoshida, M., Bielsky, I.F., Ross, H.E., Kawamata, M., Onaka, T., Yanagisawa, T., Kimura, T., Matzuk, M.M., Young, L.J., Nishimori, K., 2005. Pervasive social deficits, but normal parturition, in oxytocin receptor-deficient mice. Proc. Natl. Acad. Sci. USA 102, 16096-16101.

Togashi, K., Inada, H., Tominaga, M., 2008. Inhibition of the transient receptor potential cation channel TRPM2 by 2-aminoethoxydiphenyl borate (2-APB). Br. J. Pharmacol. 153, 1324-1330.

Wang, K., Zhang, H., Ma, D., Bucan, M., Glessner, J.T., Abrahams, B.S., Salyakina, D., Imielinski, M., Bradfield, J.P., Sleiman, P.M., Kim, C.E., Hou, C., Frackelton, E., 
Chiavacci, R., Takahashi, N., Sakurai, T., Rappaport, E., Lajonchere, C.M., Munson, J., Estes, A., Korvatska, O., Piven, J., Sonnenblick, L.I., Alvarez Retuerto, A.I., Herman, E.I., Dong, H., Hutman, T., Sigman, M., Ozonoff, S., Klin, A., Owley, T., Sweeney, J.A., Brune, C.W., Cantor, R.M., Bernier, R., Gilbert, J.R., Cuccaro, M.L., McMahon, W.M., Miller, J., State, M.W., Wassink, T.H., Coon, H., Levy, S.E., Schultz, R.T., Nurnberger, J.I., Haines, J.L., Sutcliffe, J.S., Cook, E.H., Minshew, N.J., Buxbaum, J.D., Dawson, G., Grant, S.F., Geschwind, D.H., Pericak-Vance, M.A., Schellenberg, G.D., Hakonarson, H., 2009. Common genetic variants on 5p14.1 associate with autism spectrum disorders. Nature 459, 528-533. Wermter, A.K., Kamp-Becker, I., Hesse, P., Schulte-Körne, G., Strauch, K., Remschmidt, H., 2010. Evidence for the involvement of genetic variation in the oxytocin receptor gene (OXTR) in the etiology of autistic disorders on high-functioning level. Am. J. Med. Genet. B Neuropsychiatr. Genet. 153B, 629-639.

Wing, L., Leekam, S.R., Libby, S.J., Gould, J., Larcombe, M., 2001. The diagnostic interview for social and communication disorders: background, inter-rater reliability and clinical use. J. Child Psychol, Psychiatry, 43, 307-325.

Winslow, J.T., Insel, T.R., 2004. Neuroendocrine basis of social recognition. Curr. Opin. Neurobiol. 14, 248-253.

Yagui, K., Shimada, F., Mimura, M., Hashimoto, N., Suzuki, Y., Tokuyama, Y., Nata, K., Tohgo, A., Ikehata, F., Takasawa, S., Okamoto, H., Makino, H., Saito, Y., Kanatsuka, A., 1998. A missense mutation in the CD38 gene, a novel factor for insulin secretion: association with Type II diabetes mellitus in Japanese subjects and evidence of abnormal function when expressed in vitro. Diabetologia 41, 1024-1028.

Yamasue, H., Kuwabara, H., Kawakubo, Y., Kasai, K., 2009. Oxytocin, sexually dimorphic features of the social brain, and autism. Psychiatry Clin. Neurosci. 63, 129-140.

Young, L.J., 2007. Regulating the social brain: a new role for CD38. Neuron. 54, 353-356.

Young, L.J., Muns, S., Wang, Z., Insel, T.R., 1997. Changes in oxytocin receptor mRNA in rat brain during pregnancy and the effects of estrogen and interleukin- 6 . J. Neuroendocrinol. 9, 859-865. 
Young, L.J., Wang, Z., 2004. The neurobiology of pair bonding. Nat. Neurosci. 7, 1048-1054.

Yoshida, M., Takayanagi, Y., Inoue K., Kimura. T., Young, L.J., Onaka, T., Nishimori, K., 2009. Evidence that oxytocin exerts anxiolytic effects via oxytocin receptor expressed in serotonergic neurons in mice. J. Neurosci. 29, 2259-2271.

Zak, P.J., Stanton, A.A., Ahmadi, S., 2007. Oxytocin increases generosity in humans. PLoS ONE 2 e1128. 
Table 1. Personal use of oxytocin for over 3 months by male ASD patients with severe mental deficit with (case 1) or without (others) the R104W SNP

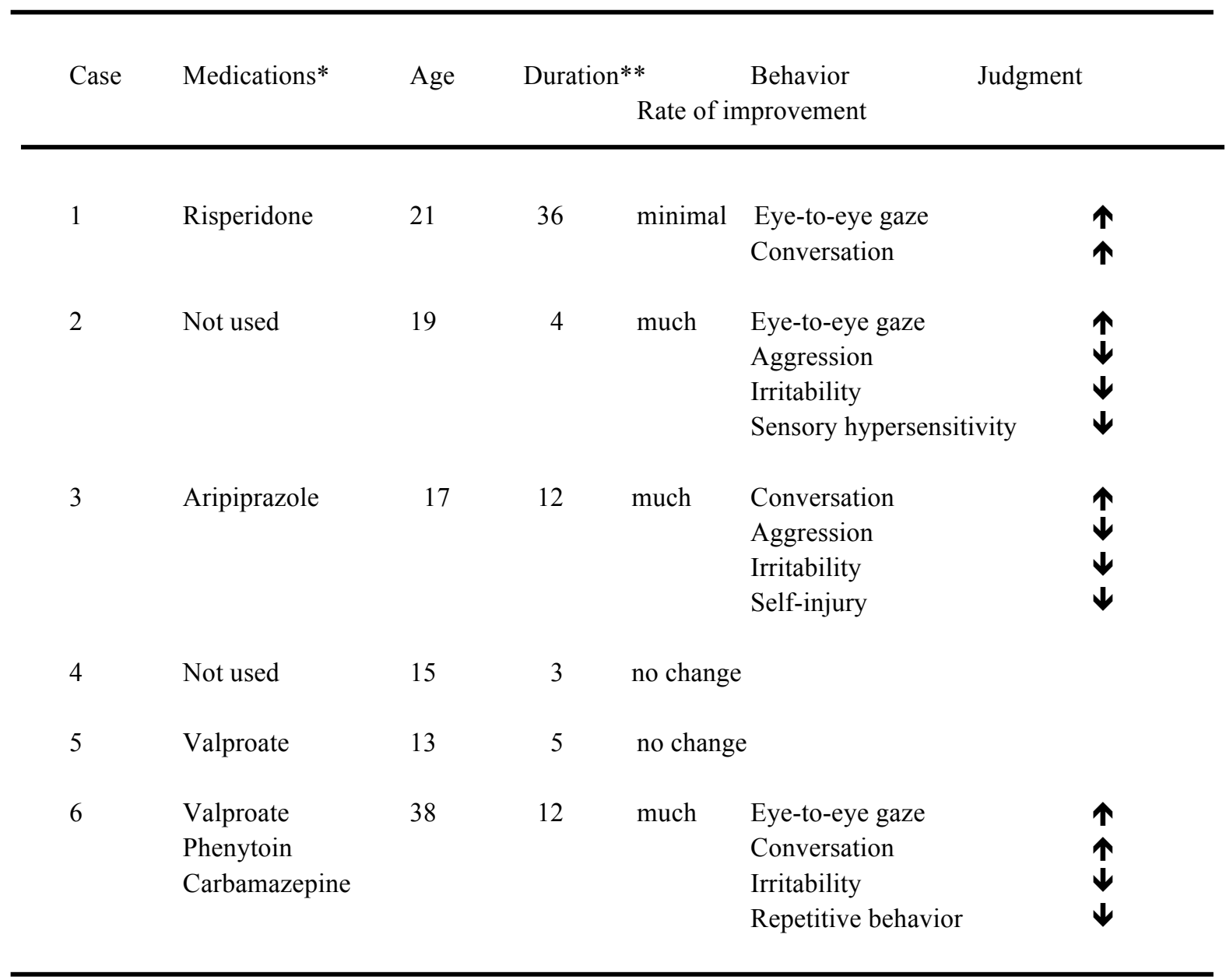

*Medication indicates simultaneous treatment with drugs during intranasal OXT administration.

** Period of daily intake of OXT in months. 


\section{Figure legends}

Fig, 1 Social behavior of CD38 knockout mice and effects of oxytocin injection or lentiviral infection. Double staining for oxytocin (OXT, green) and CD38 (red) in the hypothalamus of male wild-type (A) or $C d 38^{-/-}$(B) mice. (C). Investigation behavior of a male to the anogenital region of an intruder female. (D). Decrease of investigation time in WT $(+/+)$ or no decrease in $C d 38^{-/}(-/-)$males. (E). Behavioral recovery in males subcutaneously injected with OXT $(+\mathrm{OXT})$ and no recovery in control mice injected with saline $(+\mathrm{NaCl})$ or arginine vasopressin $(+\mathrm{AVP})$. $(\mathrm{F})$. Average investigation time of two genotypes with or without local re-expression of intact human CD38 or mutant CD38 (R140W) in the hypothalamic regions. Retrieval behavior of wild-type (G) or $C d 38^{-/-}(\mathrm{H})$ dams. (I). Average time required to retrieve 5 pups by dams of two genotypes.

Fig. 2. Oxytocin or vasopressin levels in the plasma and CSF of male mice of two genotypes.

Fig. 3 Regulatory mechanisms affecting oxytocin activity in the context of social behavior. Regulation at the level of central OXT secretion is due to calcium amplification (CICR) by CD38 and cADPR, which seems to be critical for social recognition and behavior. 
Fig. 4. Changes in $\left[\mathrm{Ca}^{2+}\right]_{i}$ induced by extracellular application of cADPR were coactivated by heat in NG 108-15 cells. (A and B). Representative images of fluorescence changes in NG108-15 cells. cADPR $(50 \mu \mathrm{M})$ was applied extracellularly at the arrow. $\left[\mathrm{Ca}^{2+}\right]_{\mathrm{i}}$ was measured at $35^{\circ} \mathrm{C}(\mathrm{A})$ or $40^{\circ} \mathrm{C}(\mathrm{B})$. Bar, $10 \mu \mathrm{m}$. White arrows and arrowheads show Oregon Green staining with a large change after stimulation. Inset, a larger montage of cells indicated by the arrows. (C) Time courses of changes in $\left[\mathrm{Ca}^{2+}\right]_{\mathrm{i}}$ drawn from fluorescence imaging comparing stimulation at $35^{\circ} \mathrm{C}$ and $40^{\circ} \mathrm{C}$ in the presence of extracellular cADPR. Data are shown as changes in fluorescence intensity divided by the resting state, i.e., $\Delta \mathrm{F}_{0} / \mathrm{F}_{1}$, as means $\pm \operatorname{SEM}(n=4-6)$. (D) $\left[\mathrm{Ca}^{2+}\right]_{\mathrm{i}}$ changes obtained in NG108-15 cells challenged by heat (from $35^{\circ} \mathrm{C}$ to $40^{\circ} \mathrm{C}$ ) and extracellular cADPR $(50 \mu \mathrm{M})$ in the presence $(\diamond)$ or absence $(\Delta)$ of extracellular $\mathrm{Ca}^{2+}$. The effects of 2-APB on $\left[\mathrm{Ca}^{2+}\right]_{\mathrm{i}}$ change with heat and cADPR are indicated by open circles $(\mathrm{O})$. Values are means \pm SEM of $3-5$ cells.

Fig. 5 Schematic representation of how oxytocin (OXT) is released after oxytocin receptor (OXTR) stimulation without depolarization via the calcium (black dots) amplification signal of $\mathrm{Ca}^{2+}$-induced $\mathrm{Ca}^{2+}$ release (CICR) essentially regulated by cyclic ADP-ribose (cADPR). CD38 with ADP-ribosyl cyclase activity in OXT-producing neurons in the hypothalamus, regulated by protein kinase $\mathrm{C}(\mathrm{PKC})$, can catalyze cADPR from $\beta$-NAD ${ }^{+}$on either the intracellular or extracellular side. cADPR together with heat activate TRPM2 cation channels and facilitate $\mathrm{Ca}^{2+}$ influx and $\mathrm{Ca}^{2+}$ release from ryanodine receptors (RyR) on intracellular $\mathrm{Ca}^{2+}$ pools. OXT is released by 
increased intracellular $\mathrm{Ca}^{2+}$ concentrations, which is necessary to behave well in social interactions.

Fig. 6. Genome structure and single nucleotide polymorphisms of human CD38. CD38 and CD157, a gene duplication product and family gene, are located on the chromosome 4 p15 region with the same structure (8 exons). Locations of SNPs in intronic SNP (SNP06), rs3796863, and exonic SNP (R140W SNP), rs1800561, are shown. SNPs of major allele and minor allele are shown in red with average penetration ratios in US and Japan, respectively.

Fig. 7. Plasma oxytocin (OXT) and arginine-vasopressin (AVP) levels and two pedigrees of ASD probands with the R140W allele. (A) A plot of plasma OXT levels of 29 ASD individuals without (open circles) or with the R140W allele (pink). (B). A scatter plot of OXT and AVP levels ASD individuals without (closed circles) or with the R140W allele (pink). (C and D) Pedigrees of 2 ASD probands. Subjects represent carriers of the R140W allele (filled symbols) or those without (open). Green symbols indicate no analysis. Arrows, proband, Asp, Asperger's disorder. (E). Plasma oxytocin and vasopressin levels in control subjects with or without (R140; $n=10$, green or blue bars) heterozygous R140W allele. Circles denote females and diamonds or squares indicate males. Note that the plasma OXT level in W140 carriers in non-idiopathic controls was not low. 
Fig. 8 Potential usage of retinoids (vitamin A analogs) or nasal oxytocin for ASD subjects. Expected malfunction caused by CD38 NPs. All-trans retinoic acid can induce CD38 transcription and results in higher CD38 expression. To rescue lower plasma or brain OXT levels in ASD patients, OXT may be applied by the nasal OXT spray method.

Fig. 9. Hypothesis of how single nucleotide polymorphisms (SNPs) lead to autism spectrum disorder (ASD) or not (non-ASD). rs3796863 and rs1800561 SNPs of human $C D 38$ may cause lower levels of oxytocin (OXT) in the brain or plasma, which could be used as biomarkers, through lowering the expression or enzymatic activity as the CD38 endophenotype. The low plasma OXT level is also produced by other unknown factors than CD38 SNPs (other causes). ASD may be triggered by other strong risk factors and/or other weaker protective factors), while ASD may not be induced by other weaker risk factors and/or other strong protective factors, including female hormones, such as OXT. 


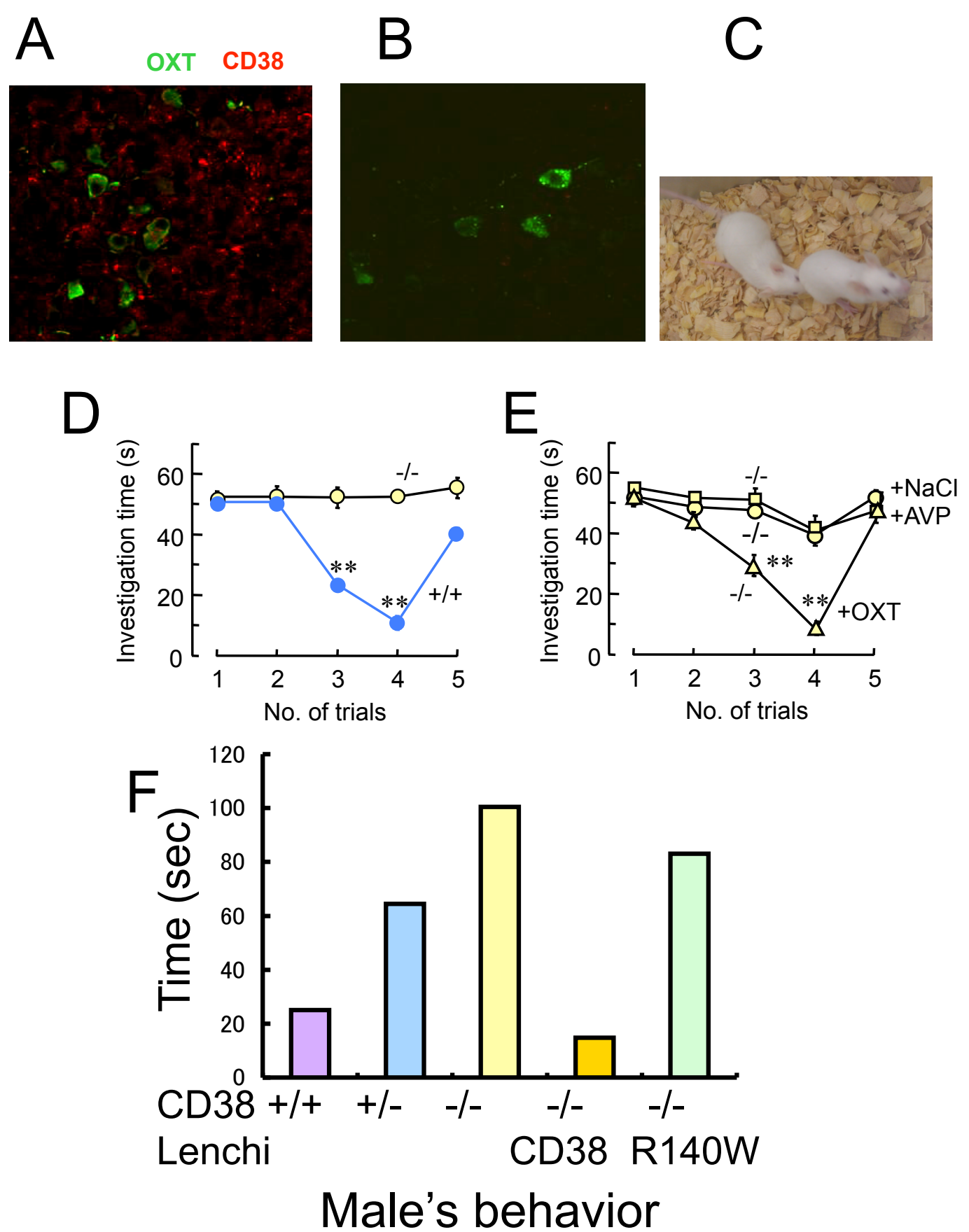

G

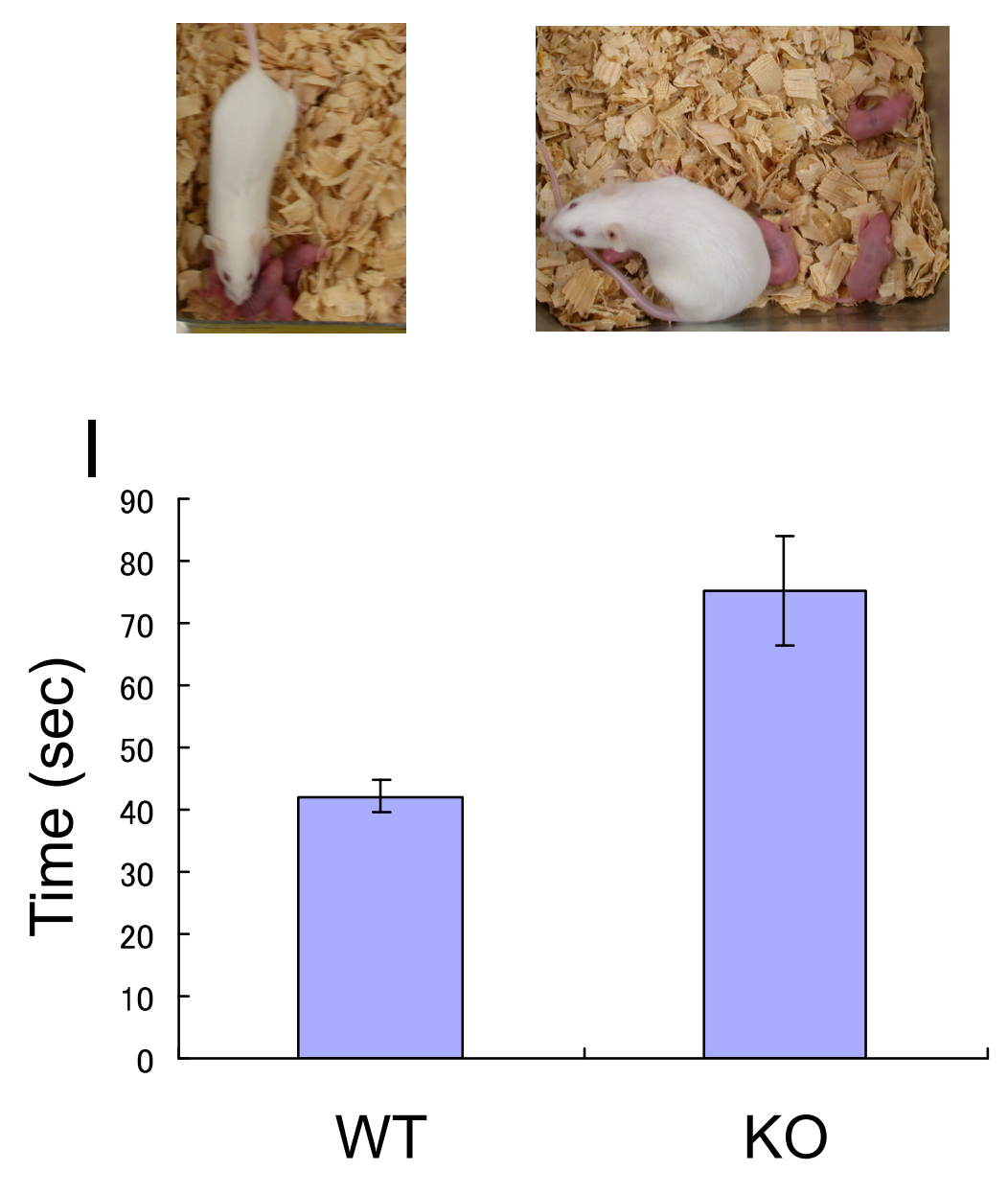

Dam's behavior

Fig. 1 

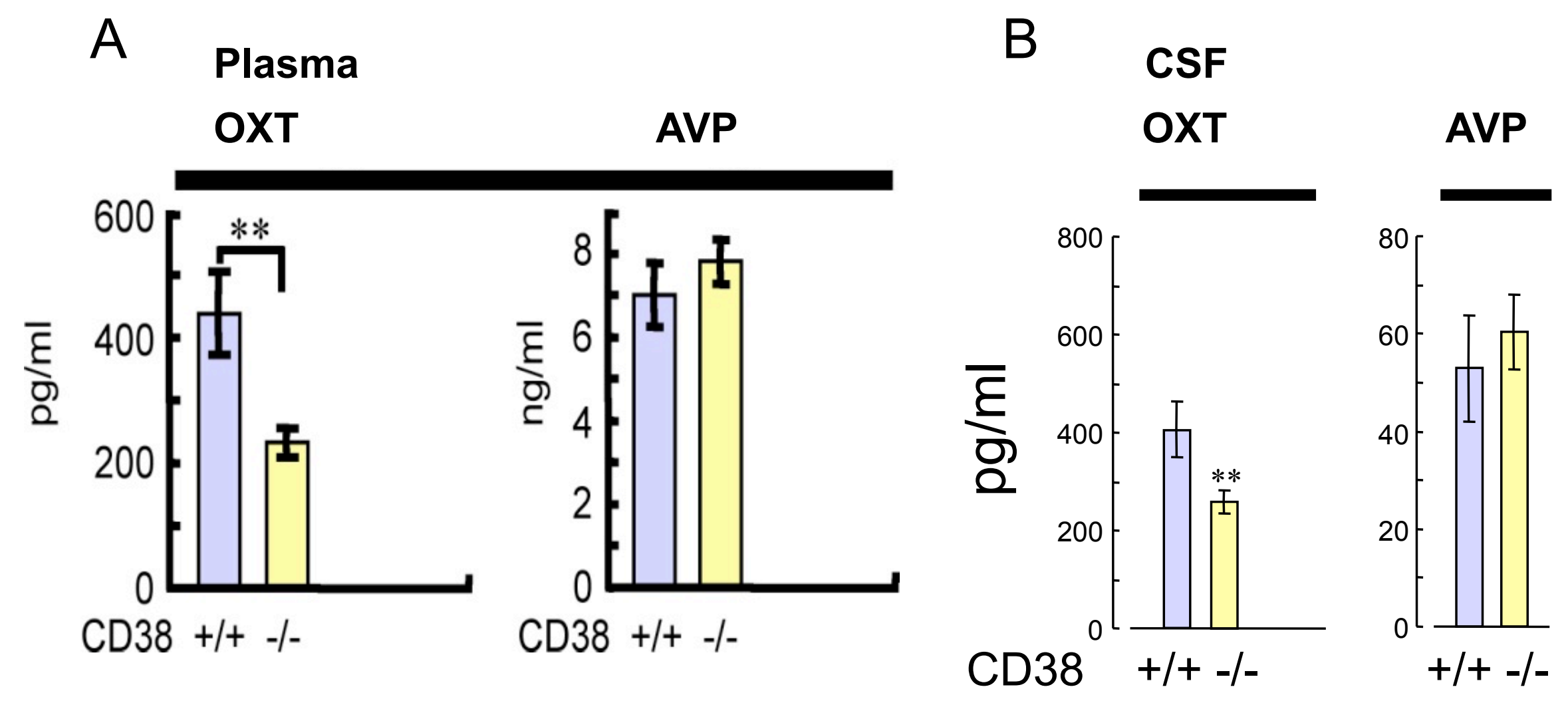

Fig. 2 


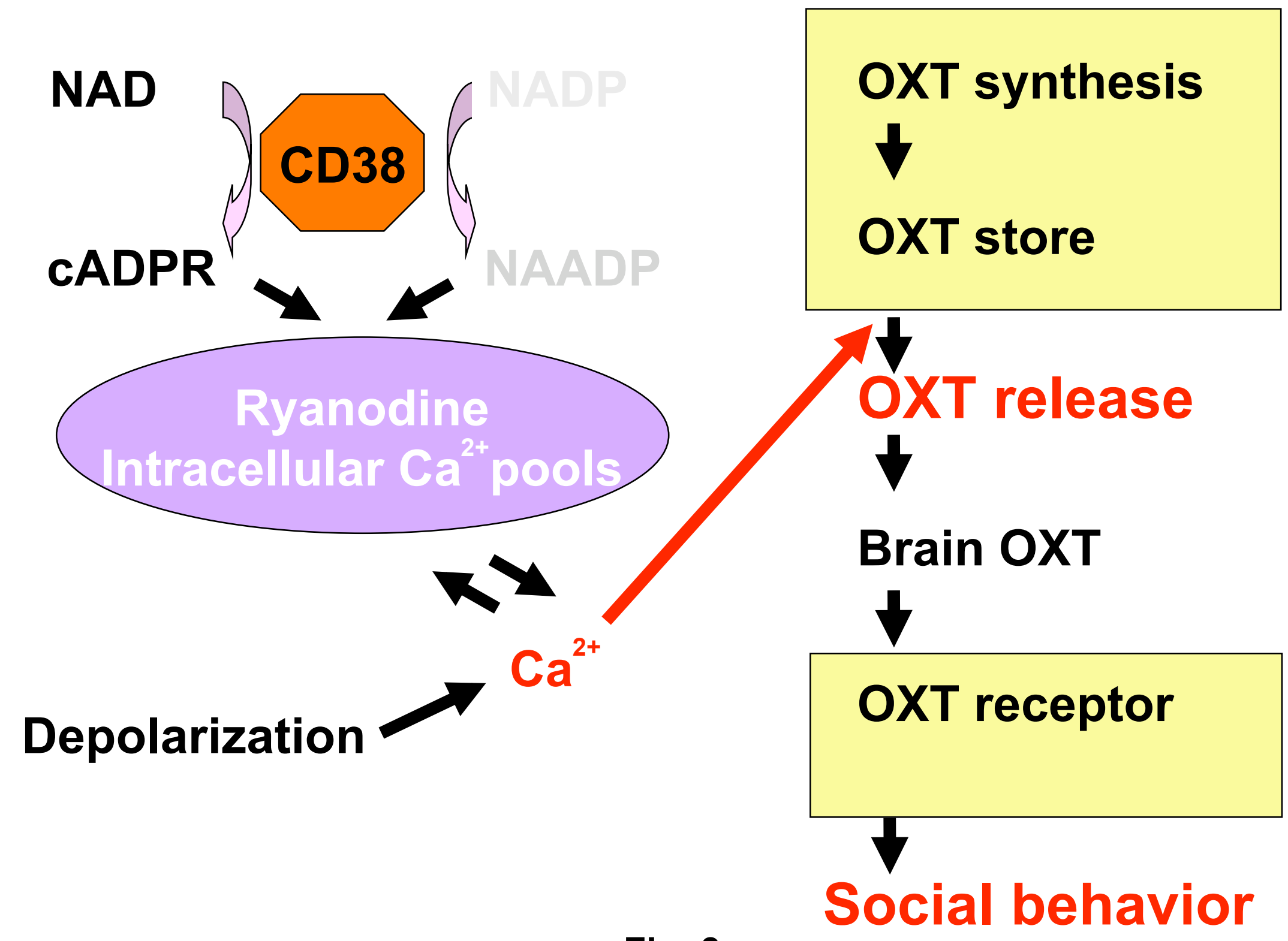

Fig. 3 

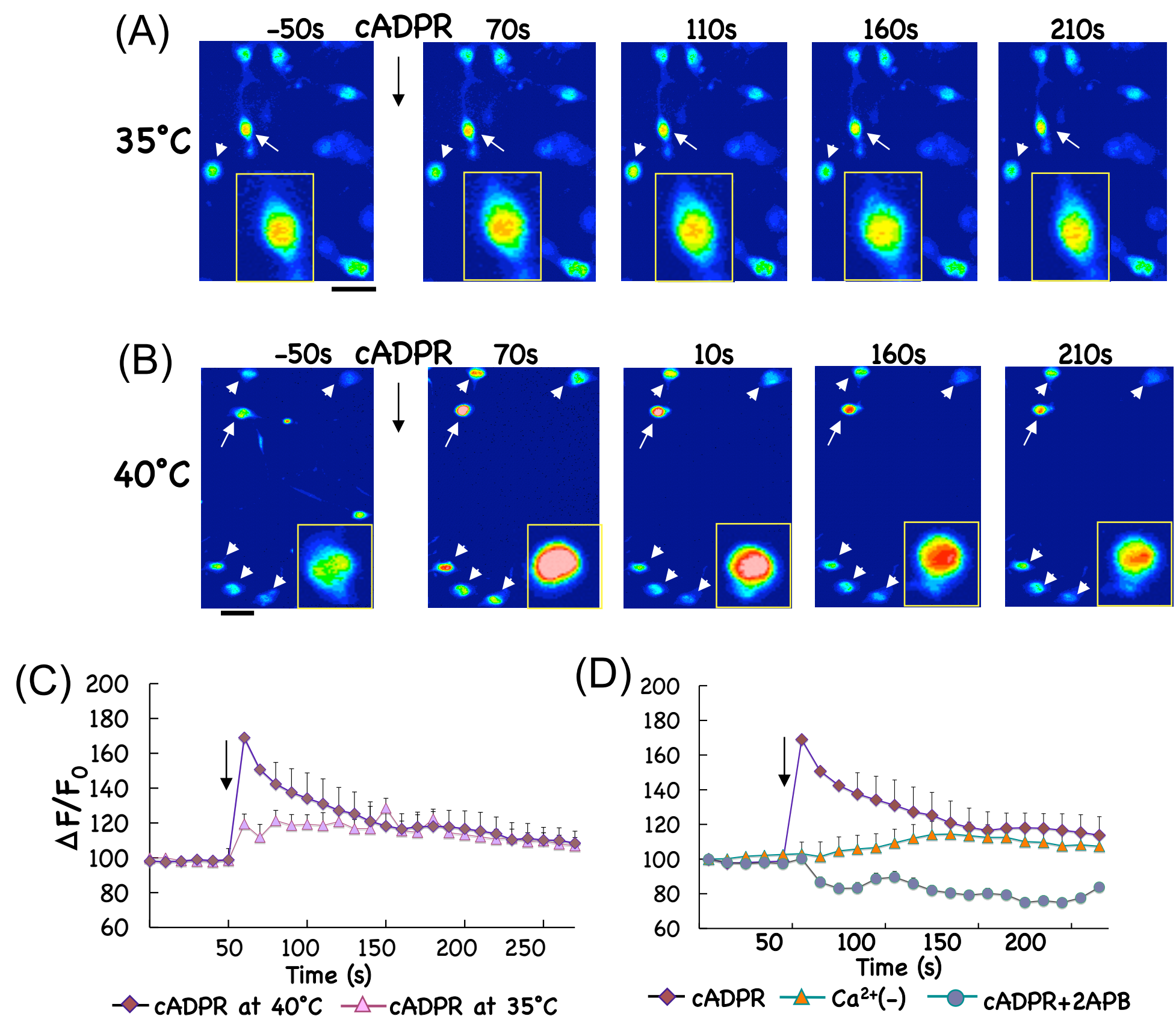

Fig. 4 


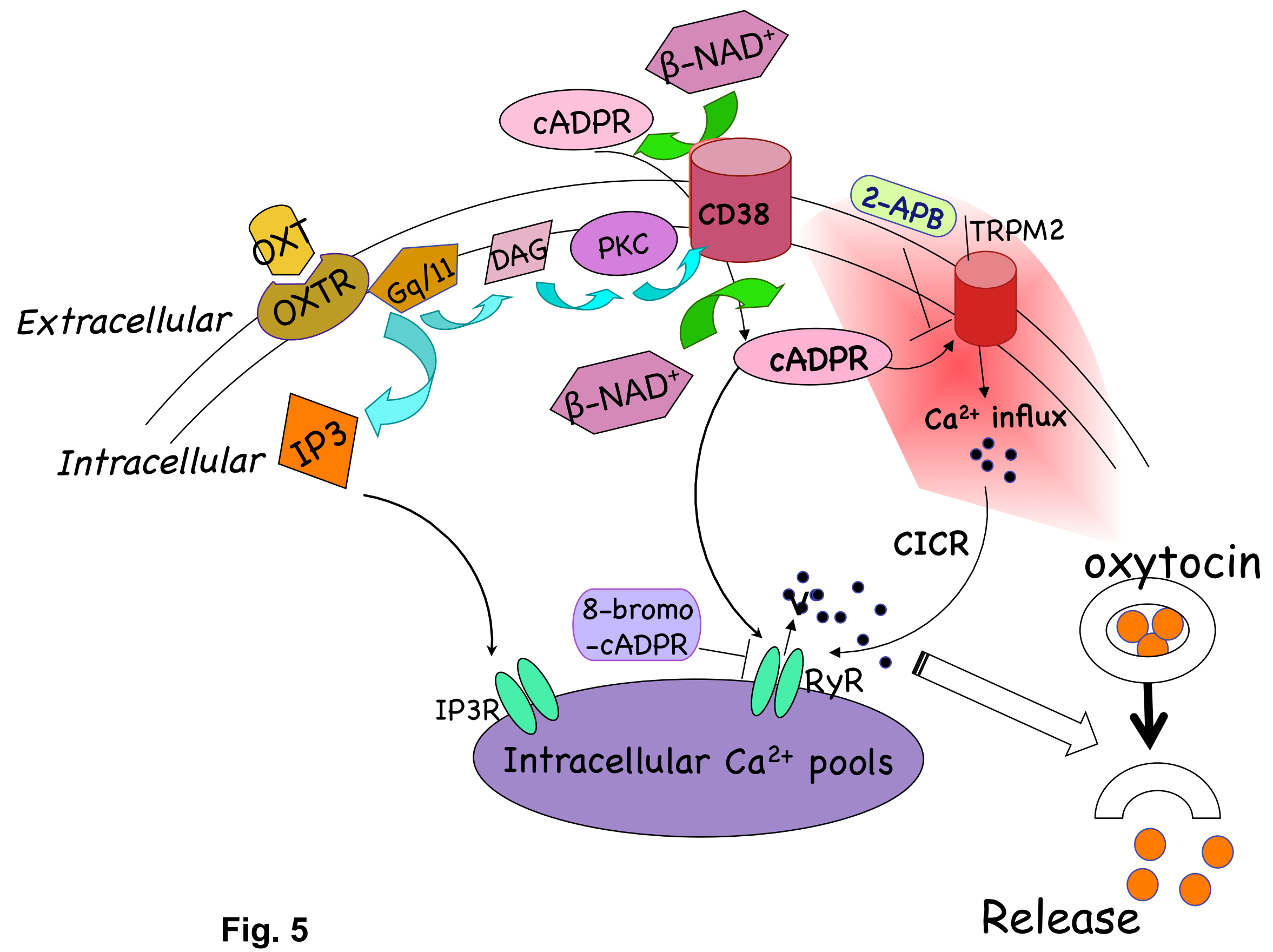




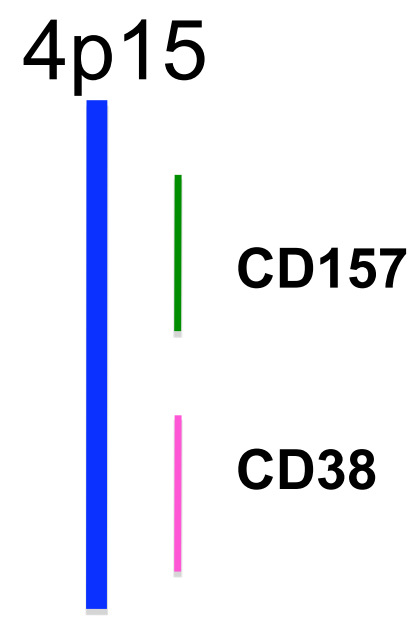

centromere

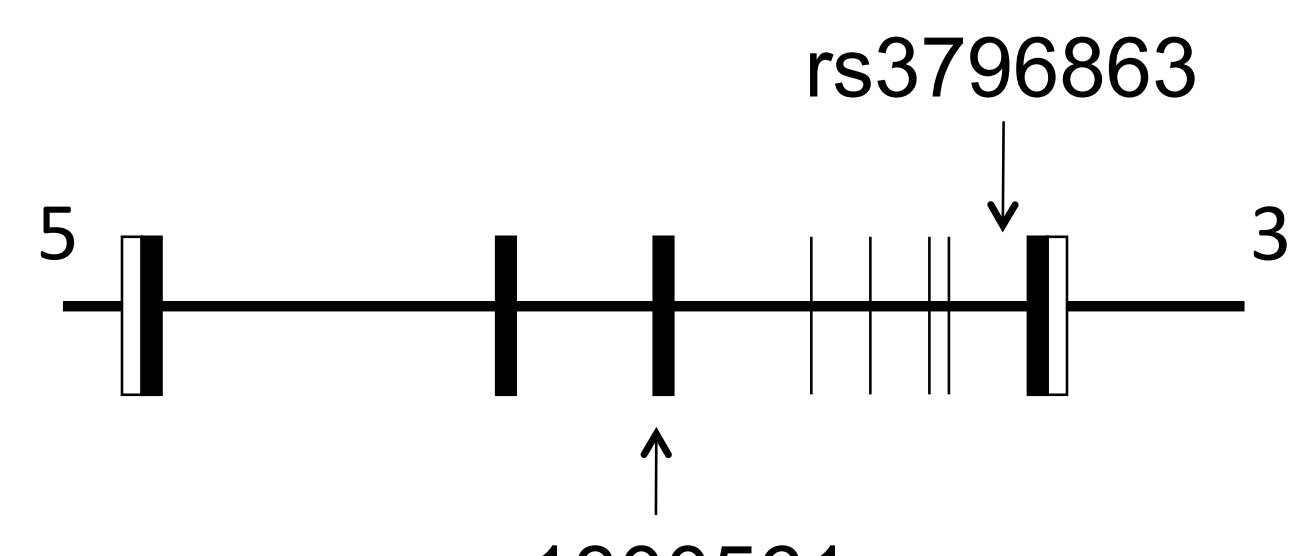

rs1800561

- SNP06 (rs3796863)

GGGAGGGGAGCTATCCATGCCACCTGCTGGTCA $72 \%$

GGGAGGGGAGCTATCCATGCCACCTGATGGTCA $28 \%$

- SNP13 R140W (rs1800561)

TGGCCCATCAGTTCACACAGGTCCAGCGGGACA 95-99\% TGGCCCATCAGTTCACACAGGTCCAGTGGGACA 5- $1 \%$

Fig. 6 


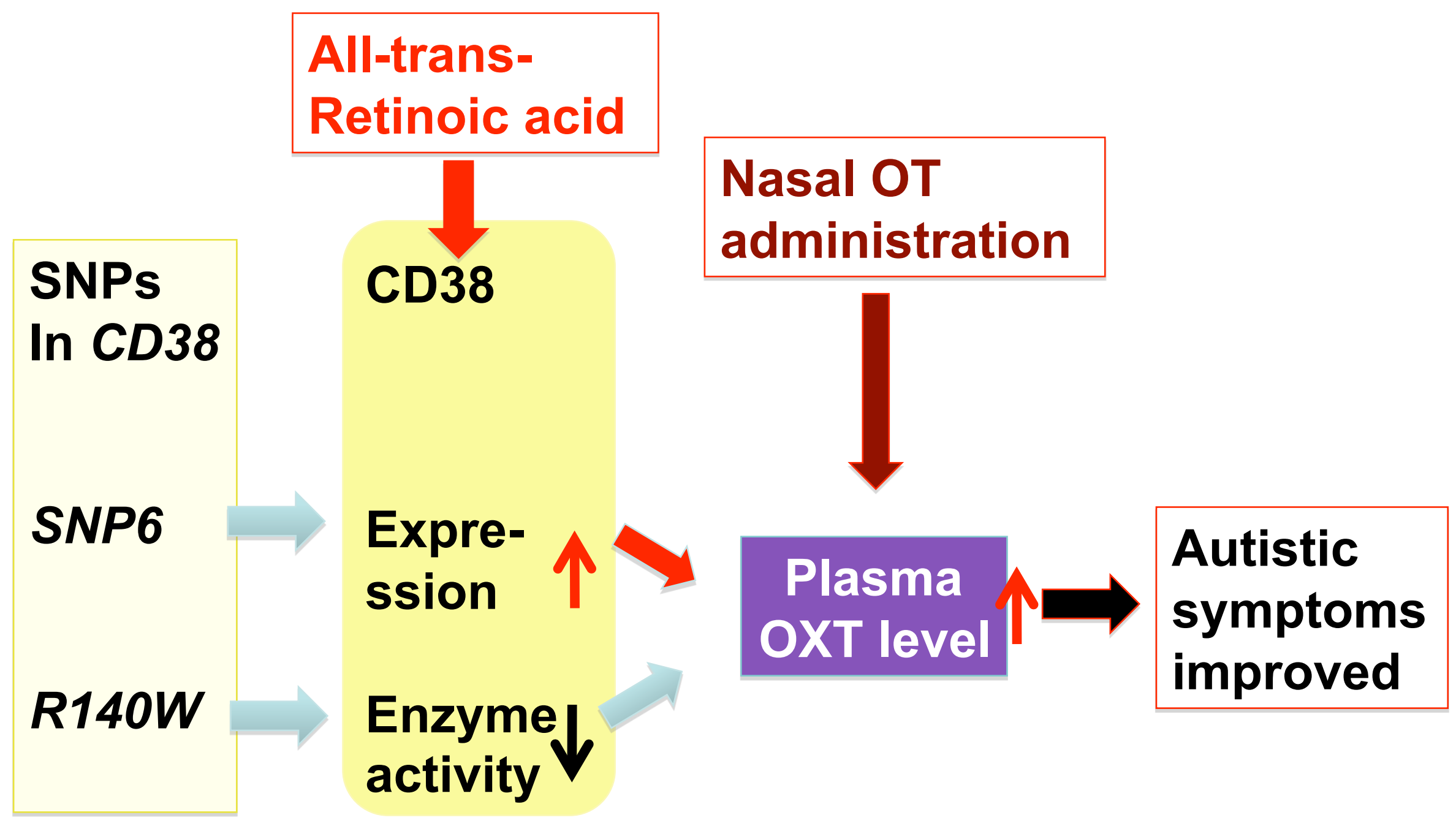

Fig. 7 

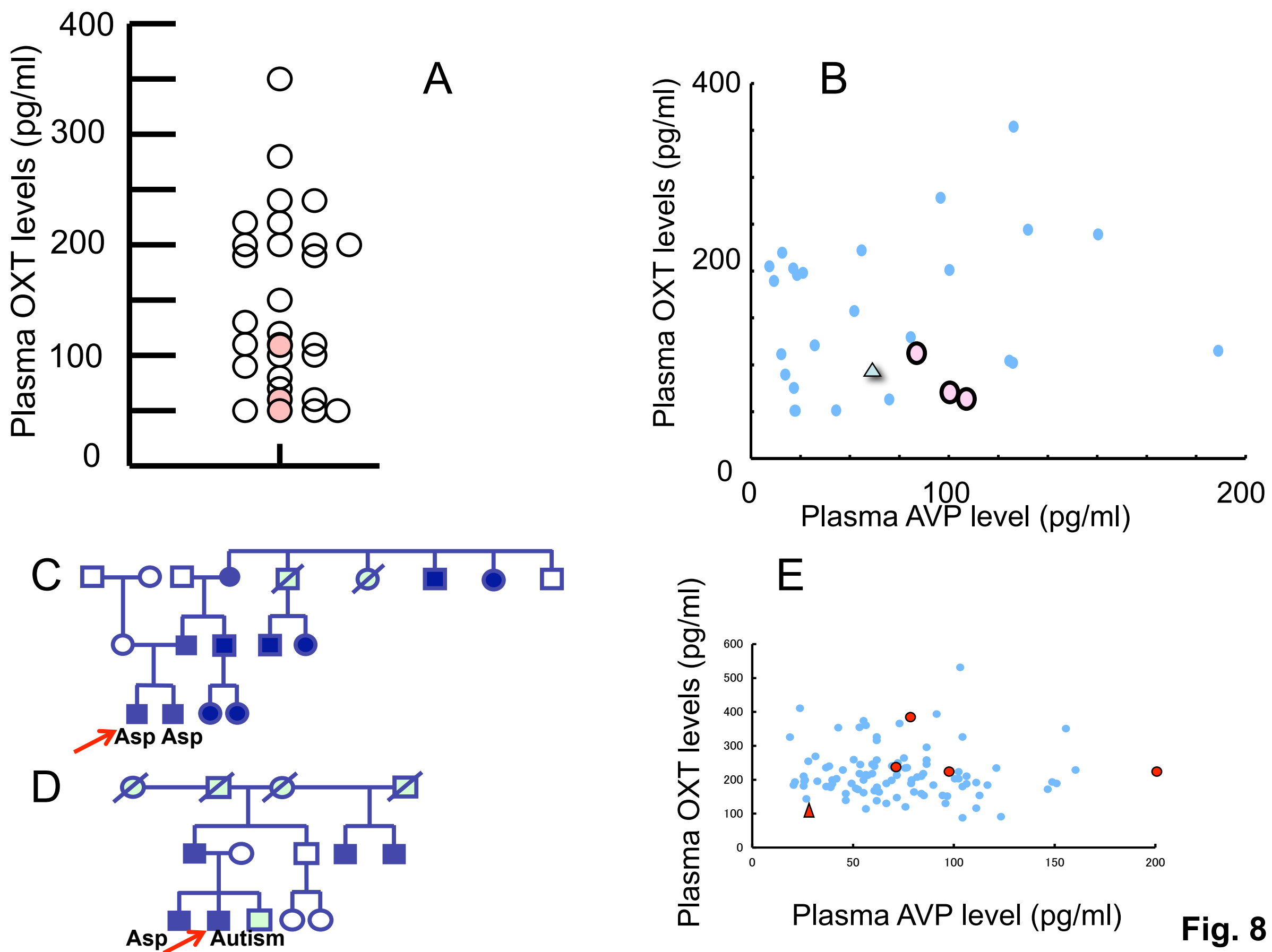

Fig. 8 
(Genetic variants)

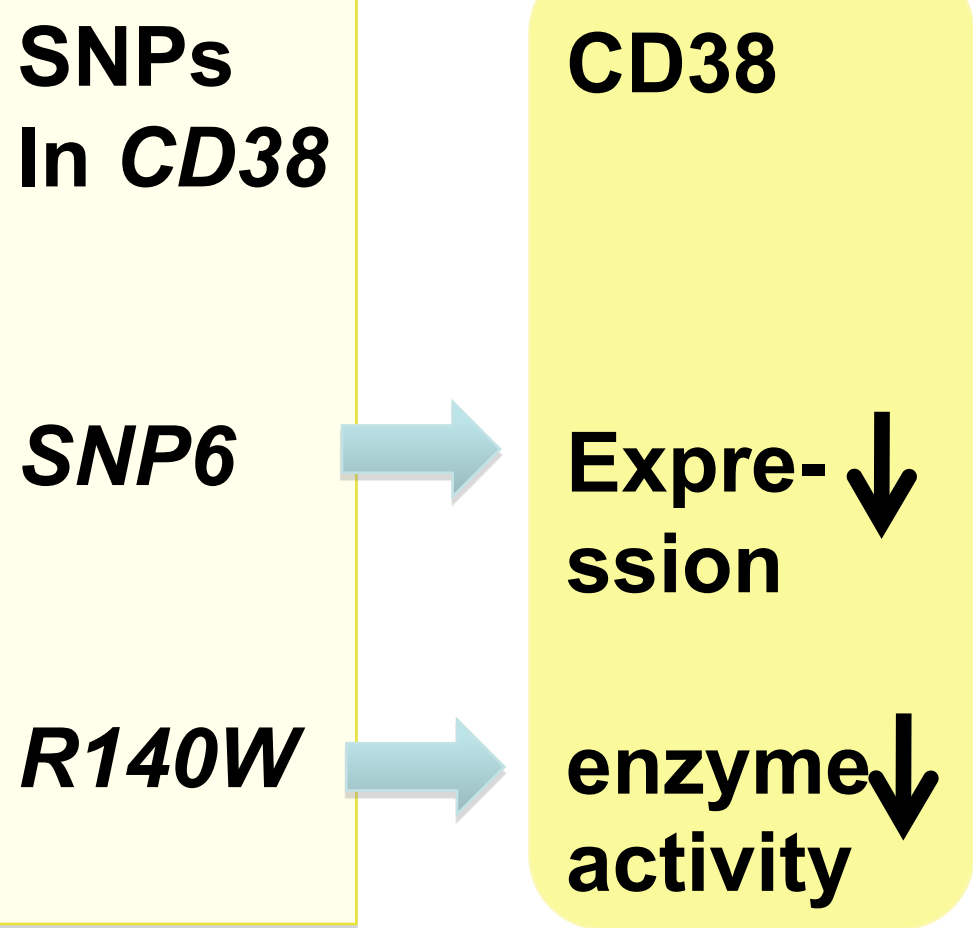

CD38
(Endophenotype)

$$
\text { Other risk factors (+++) }
$$

protective factors $(+)$

\section{ASD}

\section{(Biomarker)}

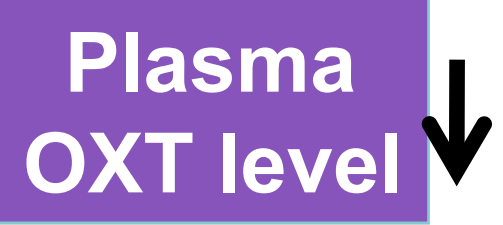

Other risk factors protective factors (+++)

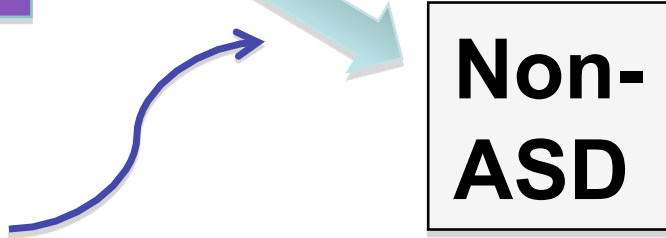

\section{Other}

causes

Fig. 9 